\title{
Novel Method and Apparatus Design for Testing Small Magnetocaloric Samples
}

\author{
M. A. Kedzierski \\ W. V. Payne \\ H. M. Skye
}

This publication is available free of charge from:

http://dx.doi.org/10.6028/NIST.TN.1931 


\title{
NIST Technical Note 1931
}

\section{Novel Method and Apparatus Design for Testing Small Magnetocaloric Samples}

\author{
M. A. Kedzierski \\ W. V. Payne \\ H. M. Skye \\ Energy and Environment Division \\ Engineering Laboratory
}

This publication is available free of charge from:

http://dx.doi.org/10.6028/NIST.TN.1931

September 2016

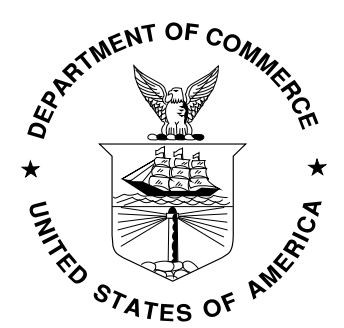

U.S. Department of Commerce

Penny Pritzker, Secretary

National Institute of Standards and Technology Willie May, Under Secretary of Commerce for Standards and Technology and Director 
Certain commercial entities, equipment, or materials may be identified in this document in order to describe an experimental procedure or concept adequately. Such identification is not intended to imply recommendation or endorsement by the National Institute of Standards and Technology, nor is it intended to imply that the entities, materials, or equipment are necessarily the best available for the purpose.

National Institute of Standards and Technology Technical Note 1931 Natl. Inst. Stand. Technol. Tech. Note 1931, 31 pages (September 2016) CODEN: NTNOEF

This publication is available free of charge from: http://dx.doi.org/10.6028/NIST.TN.1931 


\title{
Novel Method and Apparatus Design for Testing Small Magnetocaloric Samples
}

\author{
M. A. Kedzierski ${ }^{1}$ \\ W. V. Payne \\ H. M. Skye \\ National Institute of Standards and Technology \\ Gaithersburg, MD 20899
}

\begin{abstract}
This report presents a design for a novel test apparatus to directly measure the magnetocaloric effect (MCE). The design of the apparatus was focused primarily on being able to measure the MCE with minimized uncertainties for test samples of $5 \mathrm{~g}$. The effort is meant to aid U.S. industry in selecting new, limited-quantity magnetocaloric (MC) materials for commercial development. A different measurement approach is also required because of the small test sample size and because of the wide disagreement in the validity of some indirect measurement techniques. These concerns require an accurate and direct measure of MCE in order to develop superior room temperature magnetocaloric materials. For the test apparatus design presented here, the estimated uncertainties for the adiabatic temperature change and the increased internal energy are $0.3 \mathrm{~K}$ and $0.6 \%$ of the measurement, respectively. The small uncertainties were achieved for the small sample by leveraging the incompressibility of liquid as an amplifier to increase the sensitivity of energy measurement. Drawings, parts list, and required test equipment were specified for the construction of the test apparatus. A calibration technique using a first law of thermodynamics approach was outlined.
\end{abstract}

Keywords: magnetic refrigeration, magnetocaloric

${ }^{1}$ Corresponding author. Tel./fax: (301) 975-5282/(301) 975-8973. E-mail address: Mark.Kedzierski@NIST.gov 


\section{TABLE OF CONTENTS}

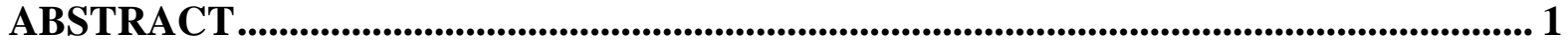

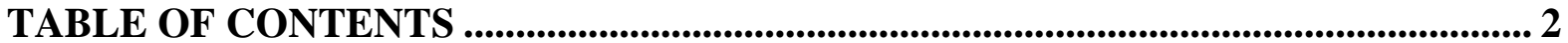

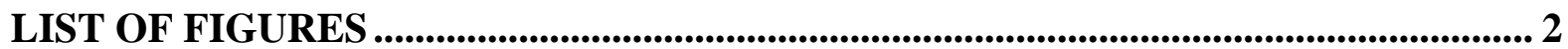

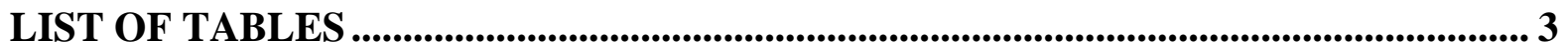

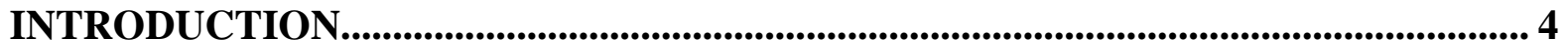

NIST TEST APPARATUS DESIGN .................................................................................. 6

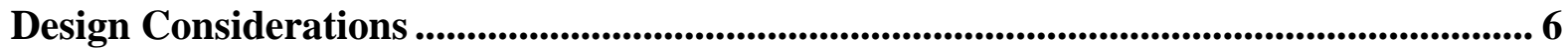

Test Apparatus Physical Overview …....................................................................... 7

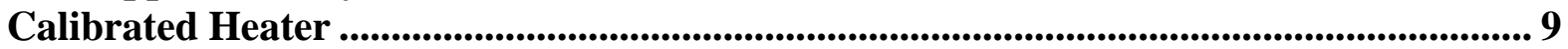

Test Chamber Liquid Selection ................................................................................................. 10

Relating Pressure to Energy ……….............................................................................................. 10

DIRECT MEASUREMENT AND CALIBRATION_.................................................. 13

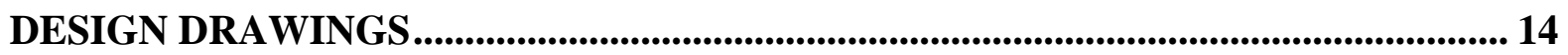

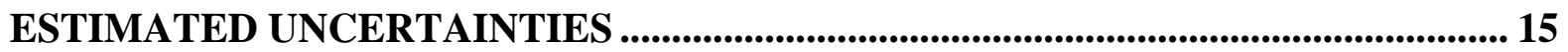

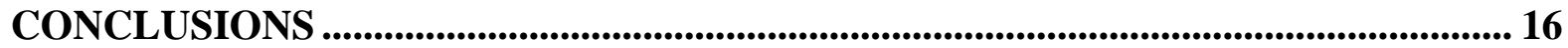

ACKNOWLEDGEMENTS .............................................................................................. 16

NOMENCLATURE........................................................................................................... 17

English symbols............................................................................................................................... 17

Greek symbols .......................................................................................................................... 17

Subscripts................................................................................................................................... 17

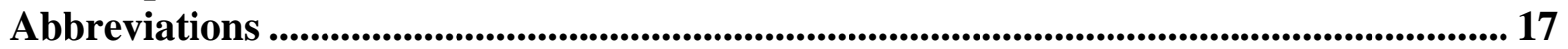

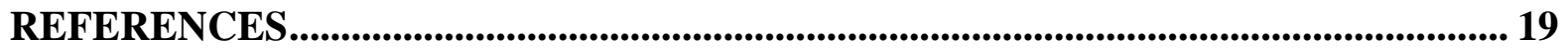

APPENDIX A: TEST EQUIPMENT ............................................................................ 31

APPENDIX B: PARTS FOR NIST FABRICATION DIVISION...................................... 32

Magnet Holders: Quantity 2 ...................................................................................................... 32

Mounting Plate .............................................................................................................................. 34

APPENDIX C: MCE TEMPERATURE CHANGE FOR POLYNOMIALS ................... 35

\section{LIST OF FIGURES}

Fig. 1 Halbach magnet with magnetic field lines (Lee, et al., 2002) ................................... 22

Fig. 2 Simple schematic of test apparatus................................................................................... 23

Fig. 3 Transient pressure pulse in test section.................................................................... 24

Fig. 4 Change in pressure for various water volumes for a magnetocaloric temperature change of $2 \mathrm{~K}, 5 \mathrm{~K}$, and $10 \mathrm{~K}$................................................................................. 25

Fig. 5 Change in pressure for various R123 volumes for a magnetocaloric temperature change of $2 \mathrm{~K}, 5 \mathrm{~K}$, and $10 \mathrm{~K}$..................................................................................... 26

Fig. 6 Example case illustrating the liquid pressure pulse for a volume of $9 \mathbf{c m}^{3}$ and an applied voltage of $20 \mathrm{~V}$ for $34.6 \mu \mathrm{s}$........................................................................... 27

Fig. 7 Example case illustrating the pressure change during cooling after a pulse for a

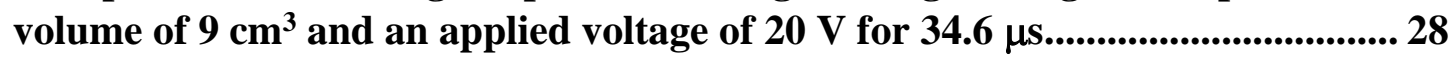

Fig. 8 Side-view schematic of test apparatus ............................................................................ 29

Fig. 9 Top-view schematic of test apparatus ............................................................................. 30

Fig. A.1 Agilent \# 81104A pulse generator ................................................................................. 31

Fig. A.2 Model 460 3-Channel Gaussmeter ................................................................................... 31

Fig. B.1 Bottom of Bar Magnetic Holder........................................................................................ 32 
Fig. B.2 Lid for Bar Magnetic Holder.

Fig. B.3 Mounting Plate .................................................................................................................. 34

\section{LIST OF TABLES}

Table 1: List of Test Apparatus Parts and Equipment ................................................ 20

Table 2: Estimated Expanded Uncertainties for Test Apparatus .................................. 21 


\section{INTRODUCTION}

A strict definition of the magnetocaloric effect (MCE) does not exist. Vodyanoy and Mnyukh (2013) define it simply as "the heat emanated or absorbed when [a] magnetic field is applied to [a] magnetic material.” McMichael et al. (1992) view the MCE as an intrinsic property of magnetic materials where a magnetic field $(B)$ causes an adiabatic temperature change in the material. Gómeza et al. (2013) state that MCE is a physical property of materials whereby the temperature and the magnetic entropy vary in the presence of a varying magnetic field. In this report, the MCE is defined as the heat (energy) increase/decrease and the corresponding temperature increase/decrease of a magnetocaloric (MC) material in the presence of a magnetic field. For this definition, the adiabatic temperature change $\left(\Delta T_{\mathrm{M}}\right)$ is the maximum temperature change for a given $\mathrm{MC}$ material exposed to a given magnetic field.

Refrigeration that relies solely on the MCE for its cooling (MC refrigeration) has been identified as one of three alternative technologies that show the most promise for displacing the currently dominant vapor compression technology (Brown and Domanski, 2014). The temperature change that is caused by exposing a MC material to a magnetic field can be used in the same way as a temperature change that is produced by a conventional vapor compression system. Either method of converting work into heat can be used as the basis for a refrigeration or airconditioning system.

The merits of MC refrigeration include the elimination of green house gases used currently as refrigerants and the potential to significantly improve the energetic efficiency of refrigeration as postulated in several theoretical studies; both these benefits would reduce the impact of refrigeration equipment on climate change. Consequently, significant research and experimental development efforts have occurred around the world in the last 20 years with the number of MCE publications and patents increasing exponentially (Yu et al., 2010).

The major obstacle to MCE technology achieving its performance potential and commercial entry is the inability of currently available MC materials to generate the required temperature increase, i.e., temperature lift. For any cooling system, the temperature lift is dictated by the requirement that heat must be transferred from the cooled environment to the ambient environment, which is order of $30 \mathrm{~K}$ for a refrigerator. The typical temperature lift achieved with Gadolinium via the MCE is of the order of $5 \mathrm{~K}$. As a consequence of this shortcoming, worldwide research has been focused on the development of new MC materials with larger MCE (Langebach et al., 2014).

Recent discussions with a National Institute of Standards and Technology (NIST) technical expert on magnetocaloric materials (Bennett, 2015) indicate a pending breakthrough in material science that will allow for the production of magnetocaloric alloys theoretically capable of $30 \mathrm{~K}$ temperature change. This level of temperature change begins to make a practical refrigeration application possible. The Center for Functional Nanomaterials at Brookhaven National Laboratory has recommended that the technical expert's proposal for obtaining alloy nanostructures should be funded to cooperatively work with NIST to investigate new MC nanomaterials alloys (Bennett, 2015). The small samples developed in the technical expert's proposal that show strong magnetic tendencies will be tested for their MCE as a function of 
applied magnetic field. The expected result is a new magnetocaloric alloy that will provide sufficient temperature lift to make a magnetic refrigerator commercially feasible.

Consequently, the goal of this investigation is to design a measurement method and a test apparatus that can be used to measure the MCE of newly developed MC materials that are expected to be available in small quantities of $5 \mathrm{~g}$ or less. It is the overall goal that MC materials can be identified that can be used to overcome the barriers to commercialization of MC refrigeration. Because of the small sample size, the instrument necessarily needs to be more sensitive than instruments that have been previously made.

\section{CURRENT STATE-OF-ART}

As outlined by Lee (2004), the common practice for measuring the MCE (adiabatic temperature change) has three main approaches. The first method is to directly measure the adiabatic temperature change by insulating the material and exposing it to a magnetic field. The remaining two methods are indirect methods for measuring the MCE that involve the measurement of the magnetization (magnetic moment) and the calculation of isothermal magnetic entropy change. The adiabatic temperature change is then calculated from the entropy change. For example, the second method, which Lee (2004) applies, uses magnetization measurements and zero-magnetic field heat capacity measurements to calculate the entropy change with Maxwell's

thermodynamic relations to determine the MCE. The third method relies on both zero-magnetic field and nonzero-magnetic field heat capacity measurements and the measured magnetic moment to calculate the entropy change.

Pecharsky and Gschneidner (1999) favor the indirect measurement methods for MCE because the uncertainties in the direct measurement have several sources, including: thermometry (with additional sensor errors caused by the changing magnetic field), magnetic field, and heat losses. In addition, the indirect measurements result in more measured quantities than just the adiabatic temperature change. Nevertheless, according to Pecharsky and Gschneidner (1999), the uncertainty ranges associated with the indirect and direct methods are comparable, being $5 \%$ to $10 \%$ and $3 \%$ to $10 \%$ for the direct and indirect methods, respectively.

However, there is reason to question the validity of the indirect measurement approach. Vodyanoy and Mnyukh (2013) state that "there is no basis for that MCE to be a change of magnetic entropy.” They justify their claim with a physical argument that the MCE is the energy of the crystal restructuring and not due to large polarization change. One might attribute these conclusions as the opinion of a few researchers and regard the indirect method as still viable. However, we also have reasons to doubt the indirect approach due to our inability to confirm the derivation of the accepted expression for the adiabatic temperature change as derived from the magnetic entropy and given by Pecharsky and Gschneidner (1999). In their derivation, the magnetic term was ignored in the expression of the first law of thermodynamics that was used to calculate the adiabatic temperature from the magnetic entropy. This omission may be what Aslani et al. (2016) call "misappropriate use of Maxwell relations" and conclude that "direct methods for measuring adiabatic temperature change must be performed.” In addition, the indirect methods cannot be used to measure the hysteresis associated with the MCE (Bennett, 2015). Consequently, considering that the direct and indirect methodologies have comparable 
uncertainties, and because the indirect method correctness has reason to be questioned, the present test apparatus design plans to use the direct method to measure the MCE.

\section{NIST TEST APPARATUS DESIGN}

The following section describes the test apparatus design by considering the physical limitations of the spatial, temporal, thermal, magnetic, and thermodynamic properties of materials that are available for its construction. First, the expected MCE is quantified in terms of magnitude and duration. Next, a technique is outlined to measure the MCE by measuring the pressure pulse that the MC material imposes on a surrounding liquid in an enclosed volume. This pressure pulse is then related to the energy pulse by using the first law of thermodynamics. The size of the test chamber that holds the liquid and the MC test sample is sized based on the properties of the liquid and the expected MCE.

\section{Design Considerations}

In order to properly design a test apparatus to directly measure the MCE, the basic mechanisms that govern the MCE phenomenon must be considered. Understanding what is to be measured and how the MCE is realized is essential for ensuring that the true effect is measured. Even though, as Vodyanoy and Mnyukh (2013) and de Oliveira and von Ranke (2010) point out, the physics of the MCE is not completely understood, a basic energy approach is sufficient for the test apparatus design. In addition, the obstacles to the accurate measurement of the MCE must be clearly identified and either eliminated or minimized. The following section outlines the measurement goals, difficulties and the solutions that were applied to the design of the test apparatus to measure the MCE.

The response of the magnetocaloric material to a changing magnetic field is to change the orientation of its atoms so that the magnetic dipoles are aligned with the magnetic field. As discussed earlier, Vodyanoy and Mnyukh (2013) prefer to attribute the MCE to crystal restructuring and the resulting latent heat of the structural phase transition, and not to polarization change. However, all that is important for the apparatus design is that the MCE, be it by either the change in orientation or the crystal restructuring, manifests itself as a change in the internal kinetic energy of the material with no change in the internal potential energy. The MCE kinetic energy increase is in addition to the pre-existing kinetic energy of the atoms, due to translational, vibrational, and rotational kinetic energies. Temperature is a measure for the level of internal kinetic energy of an atom. The increase in temperature due to the additional MCE kinetic energy is known as the magnetocaloric effect $\Delta T_{\mathrm{M}}$. The $\Delta T_{\mathrm{M}}$ is equal to the difference between the material's original ambient temperature before the application of the magnetic field $\left(T_{\mathrm{a}}\right)$ and the maximum temperature the material would have reached in the absence of heat transfer $\left(T_{\mathrm{M}}\right)$. If the material is allowed to cool back to ambient temperature while the magnetic field remains applied, then the translational, vibrational, and rotational kinetic energies are reduced leaving the internal potential energy and the MCE kinetic energy of the atom unchanged. Further reduction in the atom's kinetic energy and corresponding temperature occurs when the magnetic field is removed. If the temperature drop occurs ideally without hysteresis when the magnetic field is removed, then it will be equal to $\Delta T_{\mathrm{M}}$.

The reason that the MCE is defined for an adiabatic condition is that it represents the maximum potential for temperature change for a given magnetic field intensity. Defined in this way, the MCE is a property of the material, and it is what is to be measured with the proposed test 
apparatus. However, any arbitrary amount of heat transfer during the application of the magnetic field will lead to a corresponding reduction in the MCE that is achieved. Heat transfer from the test sample represents a loss in MCE kinetic energy that is unavailable for increasing the sample temperature. Considering this issue, the primary measurement concern is to ensure that the maximum (adiabatic) MCE kinetic energy is measured and converted into something measurable without the potential for errors due to heat transfer.

Difficulties for measuring the maximum magnetocaloric effect, i.e., the adiabatic temperature change $\left(\Delta T_{\mathrm{M}}\right)$, arise from the limited availability of the sample material mass $\left(M_{\mathrm{m}}\right)$, which will be approximately $5 \mathrm{~g}$. For this amount, it is estimated that the magnetocaloric heating effect for every $1 \mathrm{~K}$ change in temperature will be of the order of $1.2 \mathrm{~J}$ assuming that it has the same thermal and magnetic characteristics of gadolinium $(\mathrm{Gd})$ :

$$
M_{\mathrm{m}} C_{\mathrm{pm}} \Delta T=0.005 \mathrm{~kg} \cdot 230 \frac{\mathrm{J}}{\mathrm{kg} \cdot \mathrm{K}} 1 \mathrm{~K}=1.2 \mathrm{~J}
$$

where the specific heat $\left(C_{\mathrm{pm}}\right)$ of $\mathrm{Gd}$ is approximately $230 \mathrm{~J} \mathrm{~kg}^{-1} \mathrm{~K}^{-1}$ at room temperature.

Further measurement difficulties arise from the brevity of the MCE event. The kinetic energy increases the instant the magnetic field is applied and the dipoles of the atoms are realigned. As a result, the measurement technique must have a sufficiently small response time in order to capture the MCE event. Consequently, the test apparatus must be designed to measure the entirety of an energy spike of the order of a few joules without loss so that it can be converted to an adiabatic equivalent.

\section{Test Apparatus Physical Overview}

The proposed measurement concept, to enable the measurement of an energy spike of the order of $1.2 \mathrm{~J}$, is to use the incompressibility of liquid as an amplifier for the magnetocaloric heating effect. Being that the volume of the test chamber is designed to be relatively fixed (with the exception of the deflection of the pressure transducer diaphragm), liquid in the absence of gas will undergo a large change in pressure with a relatively small change in temperature. Being that pressure is directly related to temperature and energy, we consider this to be a "direct" measurement method for the MCE.

For the purpose of calibration, we propose to simulate the MCE using an Agilent \# 81104A (Fig. A.1 in Appendix A) ${ }^{2}$ pulse generator and a Nichrome wire heater. The pulse generator would be able to mock the magnetocaloric effect by delivering a voltage pulse to a resistive heater at prescribed durations of our choosing as small as a micro-second. Once the pressure pulse has been calibrated against the energy pulse, we would be able to use the calibration to test MC materials in the test apparatus.

In order to produce a MCE that is as large as practically possible for a given test sample, a

\footnotetext{
${ }^{2}$ Certain commercial equipment, instruments, or materials are identified in this paper in order to specify the experimental procedure adequately. Such identification is not intended to imply recommendation or endorsement by the National Institute of Standards and Technology, nor is it intended to imply that the materials or equipment identified are necessarily the best available for the purpose.
} 
magnetic field of the order of 2 T should be used (Bennet, 2015). Because the entire test chamber will be immersed in a constant temperature bath, permanent magnets will be used to generate the magnetic field. Magnetic fields of this order have been achieved with a Halbach array magnet shown in Fig. 1 (Lee, et al., 2002). However, as shown in Fig.1, the uniform magnetic field lines are confined to the center space of the magnet where the entire test apparatus must be placed. Considering this space limitation, the Halbach magnet is not suitable for the current test apparatus design. For this reason, paired bar magnets have been chosen to deliver the magnetic field incident to the test sample. Commercially available bar magnets of $0.8 \mathrm{~T}$ can be readily obtained in order to deliver a maximum of $1.6 \mathrm{~T}$ to the test sample. In addition, the bar magnets are planned to be placed on linear positioning devices so that the magnitude of the magnetic field can be varied by changing the proximity of the magnets to the test sample. The intensity of the magnetic field will be measured and calibrated with respect to magnet position by using a duplicate test section with a Hall sensor assembly in place of the test sample in order to measure the magnetic field as it exists in the test apparatus with the sample. ${ }^{3}$ A three-channel Gaussmeter is required to obtain the measurements from the Hall sensor. Specifications for the Gaussmeter, the Hall sensor, the bar magnets, and the positioning device are provided in Table 1.

The linear positioners need to be custom built with nonmagnetic material. The stage and the driving mechanism is planned to be aluminum and bronze, respectively. In addition, a bronze leadscrew will be used to advance the stage to overcome the large repulsive forces produced by the two bar magnets. Bronze anti-backlash nuts and bearings will also be used. Aluminum boxes are planned to be made by the NIST Fabrication Division to encase each magnet. The side walls of the box will be wide and thick enough to accept holes through which it will be bolted to the stage of the positioners. Drawings of these magnet holders are provided in Appendix B.

Figure 2 shows a simplified schematic of the test apparatus with the magnets and magnetic field lines. The entire apparatus will be submerged with the bar magnets in a constant temperature bath. Table 1 provides the list of parts to build the apparatus and required test equipment. The test chamber consists mainly of a pressure transducer and a valve. The pressure transducer and the liquid bath will serve as the pressure relief safety for the apparatus considering that the volume of incompressible fluid needs to be minimized. In this way, adding liquid volume to allow for plumbing a relief valve will be avoided. The body of the recommended pressure transducer from American Sensors Technologies is constructed of Austenitic or 316L stainless steel, which are both non-magnetic. All components of the pressure transducer must be nonmagnetic and it must be verified that the pressure measurements are unaffected by the magnetic field. A filling tee will be attached to the top of the valve so that the chamber can be evacuated before it is filled. It is likely that the valve will have to be attached to the pressure transducer with the sample in place.

The primary design consideration for the test section was to minimize its internal volume relative to the volume of the test sample, and for it to be nonmagnetic. The measurement concept is to fill the entire space that holds the test sample with incompressible liquid. For an incompressible liquid in a fixed volume, an increase in temperature corresponds to an increase in the pressure of the liquid. The relationship between the liquid temperature and the pressure is governed by

\footnotetext{
${ }^{3}$ The Hall sensor will measure the magnet field that is incident to the test sample. The intensity of the magnetic field as it exists in the sample can be obtained if the permeability of the sample is known.
} 
thermodynamics. Figure 3 shows the expected transient pressure response to the MCE. At time zero, the magnetic field is zero and the pressure represents the equilibrium pressure of the test chamber fluid at the bath temperature $\left(T_{b}\right)$. The MCE occurs nearly instantaneously once the magnetic field is applied. Consequently, the liquid pressure response will lag the increase in the kinetic energy of the test sample. As a result, the peak liquid pressure occurs after the end of the MCE event. In addition, the peak is smaller than what would have occurred had the test chamber been adiabatic. Because the test chamber is in a constant temperature bath, the peak pressure is reduced due to heat transfer to the bath. As the sample establishes temperature equilibrium with the bath, the pressure decreases until it is again at the initial pressure. At this point, the magnetic field can be removed to allow the temperature of the test sample to decrease. Again, the minimum temperature is greater than what it would have been had there been no heat transfer from the bath. As heat transfer occurs the pressure increases to the original pressure.

\section{Calibrated Heater}

The purpose of the calibration with the Nichrome heater is to account for the fact that the process outlined in Fig. 3 is not adiabatic. Both the tests and the calibrations will be done with the electric heater embedded within the test sample. This is to ensure that both the mass and the thermal properties of the sample-heater composite are identical for tests and calibration. The calibration will consist of joule input to the electric heater versus maximum and minimum pressures. In addition, the entire trace of pressure with respect to time will be recorded for the calibration in order to compare it to the MCE measurements for a check of any anomalous effects. It is expected that there may be a learning curve for reading and interpreting pressure traces.

According to eq. (1), $12 \mathrm{~J}$ of heating is required to raise the magnetocaloric test sample temperature by $10 \mathrm{~K}$. If the heating occurs over $36.4 \mu \mathrm{s}^{4}$, then the total power is $32.9 \times 10^{4} \mathrm{~W}$. The length $\left(L_{\mathrm{w}}\right)$ of a $1.024 \mathrm{~mm}$ diameter $\left(D_{\mathrm{w}}\right)$ Nichrome wire is planned to be limited to approximately $1 \mathrm{~mm}$ and so that it can fit within the magnetocaloric test sample. Nichrome wire has an electrical resistivity $\left(\rho_{\mathrm{e}}\right)$ of $1 \times 10^{-6} \Omega$-m. For a wire of circular cross-section, the electrical power $\left(p_{\mathrm{e}}\right)$ is written in terms of supplied voltage $\left(V_{\mathrm{e}}\right)$ as:

$$
p_{\mathrm{e}}=\frac{V_{\mathrm{e}}^{2} \pi D_{\mathrm{w}}^{2}}{4 L_{\mathrm{w}} \rho_{\mathrm{e}}}
$$

Equation 2 can be solved for $V_{\text {e }}$ using the values provided above yielding approximately $20 \mathrm{~V}$.

Considering that temperature sensors are likely to be affected by the magnetic field (Pecharsky and Gschneidner, 2001), the pressure traces can also be calibrated to provide the temperature change of the sample. This calibration would require a temperature sensor to be embedded in the test sample. The calibration will consist of sample temperature versus maximum and minimum pressures with the electric heater on and the magnetic field off. In this way, the temperature could be indirectly measured without using the temperature sensor during the test.

\footnotetext{
4 This time interval was chosen because it was near the lower limits of what could be precisely produced and measured by the equipment.
} 


\section{Test Chamber Liquid Selection}

The next consideration in the design of the test apparatus is the choice of the fluid to surround the test sample in the test chamber. The importance of the fluid choice is significant because the fluid specific heat $\left(C_{\mathrm{pf}}\right)$ and the temperature-pressure equilibrium of the fluid determine the magnitude of the response to the MCE. The fluid response is governed by the heat exchange from the mass of the magnetocaloric material $\left(M_{\mathrm{m}}\right)$ to the mass of the fluid $\left(M_{\mathrm{f}}\right)$ and the heat loss from the fluid to the bath $\left(Q_{\mathrm{b}}\right)$. The final equilibrium temperature $\left(T_{\mathrm{eq}}\right)$ that is achieved for the two masses is represented as:

$$
M_{\mathrm{m}} \Delta T_{\mathrm{M}} C_{\mathrm{pm}}-M_{\mathrm{m}}\left(T_{\mathrm{eq}}-T_{\mathrm{b}}\right) c_{\mathrm{pm}}=M_{\mathrm{f}}\left(T_{\mathrm{eq}}-T_{\mathrm{b}}\right) c_{\mathrm{pf}}-Q_{\mathrm{b}}
$$

Equation (3) can be rearranged to solve for the increase in the fluid temperature while neglecting $Q_{\mathrm{b}}$ :

$$
T_{\text {eq }}-T_{\mathrm{b}}=\frac{M_{\mathrm{m}} \Delta T_{\mathrm{M}} c_{\mathrm{pm}}}{M_{\mathrm{f}} c_{\mathrm{pf}}+M_{\mathrm{m}} c_{\mathrm{pm}}}
$$

For an incompressible liquid, eq. (4) can be used along with the derivative of the fluid pressure $(P)$ with respect to temperature at constant density to calculate the increase in the fluid pressure from:

$$
P_{\text {eq }}-P_{\mathrm{b}}=\left.\frac{d P}{d T}\right|_{\rho}\left(T_{\text {eq }}-T_{\mathrm{b}}\right)=\left.\frac{d P}{d T}\right|_{\rho}\left[\frac{M_{\mathrm{m}} \Delta T_{\mathrm{M}} c_{\mathrm{pm}}}{M_{\mathrm{f}} c_{\mathrm{pf}}+M_{\mathrm{m}} c_{\mathrm{pm}}}\right]
$$

Here the gradient of the fluid pressure with respect to the fluid temperature is evaluated at constant density $(\rho)$. In addition, the $P_{\text {eq }}$ and the $P_{\mathrm{b}}$ are the liquid pressures evaluated at $T_{\text {eq }}$ and $T_{\mathrm{b}}$, respectively. Figure 4 uses eq. (5) to illustrate the relationship between the estimated pressure pulse and the volume of water that fills the test chamber for a given MCE. In general, small water volumes and large MCE produce large pressure pulses. Three lines are used to represent the three different magnetocaloric temperature changes. For a fluid chamber volume $\left(V_{\mathrm{c}}\right)$ of approximately $9 \mathrm{~mL}$, the pressure increase is estimated to be $36 \mathrm{kPa}, 90 \mathrm{kPa}$, and $181 \mathrm{kPa}$ for a $2 \mathrm{~K}, 5 \mathrm{~K}$, and $10 \mathrm{~K}$, respectively, temperature increase. Note that for a sample mass of $5 \mathrm{~g}$ the required volume for the sample is approximately $0.7 \mathrm{~mL}$.

Figure 5 shows the same analysis when repeated with R123 as the incompressible fluid. The resulting pressure increases for a $9 \mathrm{~mL}$ volume are substantially larger than that for water being $192 \mathrm{kPa}, 481 \mathrm{kPa}$, and $962 \mathrm{kPa}$ for a $2 \mathrm{~K}, 5 \mathrm{~K}$, and $10 \mathrm{~K}$, respectively, temperature increase. The use of R123 would permit the test chamber volume to be significantly larger. Further investigation into the choice on fluid for the test chamber may be required.

\section{Relating Pressure to Energy}

A second method for determining the pressure spike that will allow calculation of the transient behavior of the pressure increase and the pressure decrease is to use the first law of thermodynamics on a control volume that consists of the fluid and the test sample with a heating element: 


$$
q=\frac{d E}{d t}+W
$$

where $q$ is the heat transferred between the fluid in the valve and the bath, $E$ is the internal energy of the fluid, $W$ is the work done on or by the fluid, and $t$ is the variable for time. When the electric heater is used, work done on the fluid in the control volume is negative, i.e., $W=-p_{\text {e. }}$ Likewise, negative work occurs on the fluid when the magnetic field has been applied. The work is positive when the magnetic material loses kinetic energy at the moment that the magnetic field has been removed. Similarly, the $q$ is negative while the fluid is transferring heat to the bath during the application of the magnetic field and positive when the field has been removed and the fluid temperature becomes less than $T_{\mathrm{b}}$.

Note that the presence of the test sample and its thermal properties are ignored in this control volume analysis. Consequently, the analysis in this way is expected to overestimate the fluid pressure increase because it neglects the necessity of the test sample to retain some of the increased energy of the control volume. This first law analysis views the test sample as a massless heater that passes all of its generated heat instantaneously and uniformly to the liquid, which is the second error of the above analysis. However, the benefit of the analysis is that it provides an approximate transient heat transfer behavior for the heating and the cooling of the liquid.

Heat will be either convected from (-) the control volume fluid or to (+) to the control volume fluid:

$$
q=-h A\left(T_{\mathrm{f}}-T_{\mathrm{b}}\right)=-\left.h A \frac{d T}{d P}\right|_{\rho}\left(P_{\mathrm{f}}-P_{\mathrm{b}}\right)
$$

The temperature difference, $T_{\mathrm{f}}-T_{\mathrm{b}}$, is positive and negative when heat is convected from and to the control volume liquid, respectively. Consequently, because of the leading negative sign in eq. (7), the $q$ is correctly negative and positive for the two cases.

The $h$ in eq. (7) is the convection heat transfer coefficient, which was assumed to be $500 \mathrm{Wm}^{-2} \mathrm{~K}$ for the preliminary analysis. The internal surface area of the test chamber $(A)$ is presently unknown, but is estimated to be $6 \times 10^{-4} \mathrm{~m}^{2}$. The liquid temperature $\left(T_{\mathrm{f}}\right)$ is variable while the test chamber wall temperature is assumed to be constant and equal to the bath temperature $\left(T_{b}\right)$. The gradient of the temperature with respect to the fluid pressure $(d T / d P)$ is a property of the fluid and it is evaluated at the time dependent $P_{\mathrm{f}}$ and at constant density.

The rate of change of the total internal energy $(\mathrm{d} E / \mathrm{d} t)$ of the control volume can be rewritten in terms of the definition of the total enthalpy of the control volume $(H)$ as:

$$
\frac{d E}{d t}=\frac{d H_{\mathrm{f}}}{d t}-P_{\mathrm{f}} \frac{d V_{\mathrm{c}}}{d t}-V_{\mathrm{c}} \frac{d P_{\mathrm{f}}}{d t}=\frac{d P_{\mathrm{f}}}{d t}\left(\frac{d H_{\mathrm{f}}}{d P_{\mathrm{f}}}-V_{\mathrm{c}}\right)=\frac{d P_{\mathrm{f}}}{d t} V_{\mathrm{c}}\left(\rho_{\mathrm{f}} \frac{d \lambda_{\mathrm{f}}}{d P_{\mathrm{f}}}-1\right)
$$


Equation (8) was simplified by using a chain rule for the enthalpy derivative and the fact that the test chamber volume is constant. The specific liquid enthalpy $\left(\lambda_{\mathrm{f}}\right)$ and the liquid density $\left(\rho_{\mathrm{f}}\right)$ where introduced into eq. (8) so that mass independent properties could be used.

Substitution of eqs. (7), and (8) into eq. (6) yields:

$$
-\left.h A \frac{d T}{d P}\right|_{\rho}\left(P_{\mathrm{f}}-P_{\mathrm{b}}\right)=\frac{d P_{\mathrm{f}}}{d t} V_{\mathrm{c}}\left(\rho_{\mathrm{f}} \frac{d \lambda_{\mathrm{f}}}{d P_{\mathrm{f}}}-1\right) \pm W
$$

Equation (9) is valid for when work is delivered to the liquid (use $-W$ ) by either the electric heater or the magnetic material and when the magnetic material is cooling the liquid (use $+W$ ). The work term is set to zero when the electric heater is off and after either the maximum pressure $\left(P_{\mathrm{p}}\right)$ or minimum pressure has been reached.

By treating the property derivatives as constants, the solution for the electric heating case while voltage is applied to the heater and also for both the heating MCE and the cooling MCE is:

$$
P_{\mathrm{f}}=P_{\mathrm{b}}-\frac{Z}{\left.h A \frac{d T}{d P}\right|_{\rho}}\left(1-e^{\frac{-\left.h A \frac{d T}{d P}\right|_{\rho}}{V_{\mathrm{c}}\left(\rho_{\mathrm{f}} \frac{d \lambda_{\mathrm{f}}}{d P_{\mathrm{f}}}-1\right)} t}\right)
$$

Equation (10) is made valid for the electric heating case by setting $Z$ to - $p_{\text {e }}$ and it is valid for the duration of the voltage pulse $V_{\mathrm{e}}$, which is $t_{\mathrm{p}}$. Equation (10) provides the temperature increasing MCE solution when $Z$ is set to $-W$. Similarly, the cooling MCE solution is obtained when work is taken as being positive and $Z$ is set to $+W$.

The time-dependent solution of eq. (9) for when the liquid is cooling to the bath temperature after the pressure has increased to $P_{\mathrm{p}}$ due to either the electric heater or the MCE heating effect is:

$$
P_{\mathrm{f}}=P_{\mathrm{b}}+\left(P_{\mathrm{p}}-P_{\mathrm{b}}\right) e^{\frac{-\left.h A \frac{d T}{d P}\right|_{\rho}}{V_{\mathrm{c}}\left(\rho_{\mathrm{f}} \frac{d \lambda_{\mathrm{f}}}{d P_{\mathrm{f}}}-1\right)} t}
$$

Here $t=0$ corresponds to the beginning of the cooling period, which occurs immediately after the maximum pressure, $P_{\mathrm{p}}$, has occurred.

Figure 6 shows an example liquid pressure pulse for a volume of $9 \mathrm{~cm}^{3}$ and an applied voltage of $20 \mathrm{~V}$ for $34.6 \mu \mathrm{s}$. The figure shows that the pressure increase is linear with respect to time and does not increase beyond $t_{\mathrm{p}}$. The lack of a lag between the energy input and the pressure response is a result of neglecting the heat transfer interaction between the test sample and the liquid surrounding it. Figure 3 shows a potentially more realistic pressure response where the pressure curve becomes nonlinear as the temperature of the test sample and the fluid come to 
equilibrium. The value of eq. (9) is that it is a useful design tool for selecting a liquid, a liquidvolume and other design parameters.

Figure 7 uses eq. (11) to illustrate the cooling period after the pulse shown in Fig. 6. Figure 7 shows that it takes approximately $200 \mathrm{~s}$ for the liquid to cool back to the bath temperature of $300 \mathrm{~K}$.

\section{DIRECT MEASUREMENT AND CALIBRATION}

The heating and cooling pressure-time measurements and eqs. (10) and (11) can be used to calibrate the relationship between the measured pressure and the internal kinetic energy increased by the magnetocaloric effect. As stated above, the shape of the pressure-time heating curve is to be determined through experimentation. However, for the purpose of demonstrating how the calibration will be done, the pressure-time heating curve is assumed to be linear: $P_{\mathrm{f}}=P_{\mathrm{b}}$ $+C_{1}$ t, where $C_{1}$ is a fitting constant. The fit of the heating pressure curve measurements can be substituted into the general governing eq. (9) to obtain the $h A$ of the fluid-to-valve heat transfer (for use in eq. (10) and possibly eq. (11)) as:

$$
h A=\frac{1}{\left.t \frac{d T}{d P}\right|_{\rho}}\left(\frac{p_{\mathrm{e}}}{C_{1}}-V_{\mathrm{c}}\left(\rho_{\mathrm{f}} \frac{d \lambda_{\mathrm{f}}}{d P_{\mathrm{f}}}-1\right)\right)
$$

In a similar way, the cooling measurements that occur immediately after heating can be used to calculate the $h A$ by taking the natural log of both sides of eq. (11) and solving for $h A$ :

$$
h A=\frac{V_{\mathrm{c}}\left(\rho_{\mathrm{f}} \frac{d \lambda_{\mathrm{f}}}{d P_{\mathrm{f}}}-1\right)_{\mathrm{c}}}{\left.t \frac{d T}{d P}\right|_{\rho}} \ln \left[\frac{P_{\mathrm{f}}-P_{\mathrm{b}}}{P_{\mathrm{p}}-P_{\mathrm{b}}}\right]
$$

where $P_{\mathrm{p}}$ is the maximum fluid pressure just prior to cooling of the fluid. The $t$ and the $P_{\mathrm{f}}$ can be fitted to eq. (13) in order to obtain the constant $h A$. The advantage of eq. (12) over eq. (13) is that the gradient of temperature with respect to pressure is obtained for the heating case from eq. (12), which is required for calculating the adiabatic temperature increase $\left(\Delta T_{\mathrm{M}}\right)$.

The $\Delta T_{\mathrm{M}}$ of the magnetocaloric test sample for constant $d P_{\mathrm{f}} / d t$ is calculated as:

$$
\Delta T_{\mathrm{M}}=\frac{-1}{M_{\mathrm{m}} c_{\mathrm{pm}}} \int_{0}^{t_{\mathrm{p}}} W \mathrm{~d} t=\frac{\frac{d P_{\mathrm{f}}}{d t} t_{\mathrm{p}}}{M_{\mathrm{m}} c_{\mathrm{pm}}}\left[\left.\frac{h A t_{\mathrm{p}}}{2} \frac{d T}{d P}\right|_{\rho}+V_{\mathrm{c}}\left(\rho_{\mathrm{f}} \frac{d \lambda_{\mathrm{f}}}{d P_{\mathrm{f}}}-1\right)\right]
$$

for a linear pressure curve, $d P_{\mathrm{f}} / d t=C_{1}$. The negative sign is a consequence of negative work. By using eq. (14), the MCE can be obtained with both measured and calculated quantities, including the heat capacity of the test sample $\left(\mathrm{Cpm}_{\mathrm{pm}}\right)$, which will be measured with a differential scanning calorimetry (DSC). Equation (14) is also valid for determining the cooling MCE when the magnetic field is removed after the fluid and the test material have cooled to the bath 
temperature. For this case and a linear pressure with respect to time, $d P_{f} / d t$ will be negative resulting in the correct sign for $\Delta T_{\mathrm{M}}$. Appendix $\mathrm{C}$ provides an expression for $\Delta T_{\mathrm{M}}$ for nonconstant pressure gradients using quadratic and cubic pressure curve fits.

The validity of eq. (14) will be checked during calibration by comparison with the measured temperature from the thermistor imbedded in the test sample. Nara (2005) has quantified the effect that the intensity of the magnetic field $(B)$ has on thermistors with the following temperature correction $\Delta T$ :

$$
\Delta T=0.0069 B^{2}
$$

where the units of $\Delta T$ and $B$ are $\mathrm{mK}$ and Tesla, respectively. It is planned to use eq. (15) to correct the measured temperature of the magnetic material during MCE tests as a secondary measurement method for $\Delta T_{\mathrm{M}}$.

The MCE heating effect $(J)$ can be calculated from a linear pressure response (constant pressure gradient) as:

$$
J=-\int_{0}^{t_{\mathrm{p}}} W \mathrm{~d} t=\frac{d P_{\mathrm{f}}}{d t} t_{\mathrm{p}}\left[\left.\frac{h A t_{\mathrm{p}}}{2} \frac{d T}{d P}\right|_{\rho}+V_{\mathrm{c}}\left(\rho_{\mathrm{f}} \frac{d \lambda_{\mathrm{f}}}{d P_{\mathrm{f}}}-1\right)\right]
$$

The application of eq. (16) will be checked during calibration with the heater using the following equation:

$$
\int_{0}^{t_{\mathrm{p}}} p_{\mathrm{e}} \mathrm{d} t=\frac{V_{\mathrm{e}}^{2} \pi D_{\mathrm{w}}^{2}}{4 L_{\mathrm{w}} \rho_{\mathrm{e}}} t_{\mathrm{p}}=\frac{d P_{\mathrm{f}}}{d t} t_{\mathrm{p}}\left[\left.\frac{h A t_{\mathrm{p}}}{2} \frac{d T}{d P}\right|_{\rho}+V_{\mathrm{c}}\left(\rho_{\mathrm{f}} \frac{d \lambda_{\mathrm{f}}}{d P_{\mathrm{f}}}-1\right)\right]
$$

Equation (17) was derived by assuming that the pulse generator delivers a constant voltage, $V_{\mathrm{e}}$, for the duration of the pulse. Equation (17) will serve as a validation of the methodology and a check on the calculated quantities on the rightmost side of the equation. It is expected that correction constants may need to be developed as part of the calibration once the measurements have been examined in order account for the assumptions of the first law analysis. Variations of eq. (17) similar to those given in Appendix C may be used to account for potentially nonconstant pressure gradients.

\section{DESIGN DRAWINGS}

Figures 8 and 9 provide a detailed schematic of the side and top views of the test apparatus, respectively, which was shown with less detail in Fig. 2. The basic function of the test apparatus is to hold the test sample in a pressure vessel in proximity to a magnetic field. The valve and the pressure transducer serve as the pressure vessel and test chamber. The valve has three threaded ports and three shutoffs. One of the half inch National Pipe Thread (NPT) ports is for the pressure transducer and the magnetocaloric test sample. The second half inch NPT port is for a sealed wire connector for the two electrical wires of the heating element and the thermistor temperature sensor. The wires will be fished from one end of the valve to the other so that they can be embedded within the test sample. The smaller quarter inch NPT port will be used to evacuate and fill the valve with the test chamber liquid. The valve for this port will be the only valve that is to be closed. The valve/test chamber is mounted on a valve block in order to align the test sample with the axis of the two bar magnets. The bar magnets are each mounted on a 
micrometer driven positioning device. Special aluminum holders must be machined by the NIST Fabrication Division in order to securely fix the magnets to the lead screw driven positioners. Both of the positioners and the valve block are mounted onto a plate that will be fabricated. The drawings for the magnet holders and the mounting plate are provided in Appendix B.

\section{ESTIMATED UNCERTAINTIES}

All expanded measurement uncertainties $(U)$ are reported at the $95 \%$ confidence level and estimated with the law of propagation of uncertainty when a manufacturer's value is not available. The law of propagation of uncertainty was used to estimate the uncertainty of the MCE heat effect $\left(U_{\mathrm{J}}\right)$ as:

$$
\frac{U_{\mathrm{J}}}{J}=\sqrt{\left(\frac{U_{\frac{d P_{\mathrm{f}}}{d t}}}{\frac{d P_{\mathrm{f}}}{d t}}\right)^{2}+\left(\frac{U_{t_{\mathrm{p}}}}{t_{\mathrm{p}}}\right)^{2}+\left(\frac{\frac{d P_{\mathrm{f}}}{d t} t_{\mathrm{p}} U_{h A d T / d p}}{2 W}\right)^{2}+\left(\frac{\frac{d P_{\mathrm{f}}}{d t} U_{V_{\mathrm{c}}}}{W}\right)^{2}}
$$

The components of uncertainty for $J$ are: (1) the uncertainty in the measurement of the transient pressure gradient $\left(U_{d P f / d t}\right)$; (2) the uncertainty of the pulse time measurement $\left(U_{\mathrm{tp}}\right)$; (3) the uncertainty in the heat transfer constants ( $U_{h A d T / d p}$ ); and (4) the uncertainty in the liquid volume of the test chamber $\left(U_{V c}\right)$. Table 2 provides the measurement uncertainties for the new apparatus, including those for $U_{\text {tp }}$ and $U_{V c}$, which are \pm 5 ns and $\pm 4.5 \times 10^{-7} \mathrm{~m}^{3}$, respectively. The $U_{\text {tp }}$ was obtained from manufacturer specifications while the $U_{V c}$ was estimated from typical uncertainties for liquid densities. The liquid volume will be obtained by weighing the fluid in the test chamber and using the liquid density to obtain its volume. The $U_{h A d T / d p}$ was assumed to be a $\pm 3 \%$ uncertainty. Because of the multiplying constants on $U_{h A d T / d p}$ as shown in eq. (18), this uncertainty can be as large as $\pm 300 \%$ and still have a negligible effect on the value of $U_{\mathrm{J}}$. The relative uncertainty of the transient pressure gradient was estimated from the uncertainties of the pressure and time measurements shown in Table 2 to be \pm 0.006 (i.e., $\pm 0.6 \%$ ). If there is a large scatter in the pressure versus time measurement, this uncertainty will be underestimated. Conversely, if there is a small scatter in the data, the uncertainty will be overestimated. For a $t_{\mathrm{p}}$ of $34.6 \mu \mathrm{s}$, all of the uncertainty components are negligible compared to the contribution of the uncertainty of the transient pressure gradient. For a $t_{\mathrm{p}}$ of $34.6 \mu \mathrm{s}$, the estimated uncertainty for $J$ for a $5 \mathrm{~g}$ sample and a peak pressure of $36 \mathrm{kPa}$ is $\pm 0.6 \%$.

Because heat transfer from the test sample to the liquid requires time to occur, and the first law analysis assumes instantaneous transfer of heat from the test sample to the liquid, the time to reach the peak liquid pressure $\left(t_{\mathrm{p}}\right)$ is likely to be larger than $34.6 \mu$ s and comparable to the cooling time shown in Fig. 7, which is of the order of 3 minutes. For this situation, the uncertainty for $J$ will remain $\pm 0.6 \%$ for the above conditions. Just to provide an idea for the influence of $t_{\mathrm{p}}$ on the uncertainty, if the pulse time is decreased to $0.6 \mu \mathrm{s}$, the uncertainty in time becomes the dominant uncertainty and increases the $U_{\mathrm{J}}$ to approximately $\pm 1 \%$.

The law of propagation of uncertainty was also used to estimate the uncertainty of the adiabatic temperature change $\left(U_{\Delta \mathrm{T}}\right)$ as: 


$$
\frac{U_{\Delta \mathrm{T}}}{\Delta T_{\mathrm{M}}}=\sqrt{\left(\frac{U_{\mathrm{J}}}{J}\right)^{2}+\left(\frac{U_{c_{\mathrm{pm}}}}{c_{\mathrm{pm}}}\right)^{2}+\left(\frac{U_{\mathrm{M}}}{M_{\mathrm{m}}}\right)^{2}}
$$

By using the uncertainties provided in Table 2 for the specific heat of the test sample $\left(U_{c_{\mathrm{pm}}}\right)$ and that for the measured mass of the test sample $\left(U_{\mathrm{M}}\right)$ the uncertainty of $\Delta T_{\mathrm{M}}$ was calculated as a constant $\pm 3 \%$ of the measurement, which is $0.3 \mathrm{~K}$ for a $\Delta T_{\mathrm{M}}$ of $10 \mathrm{~K}$. The estimate is consistent with the uncertainty range given by Pecharsky and Gschneidner (1999) direct methods, which is $3 \%$ to $10 \%$ of the measurements. It should be noted that this methodology meets the lower end of the typical uncertainty while achieving it for test samples of abnormally small mass. In addition, the uncertainty in $U_{\Delta \mathrm{T}}$ is mainly due to the uncertainty in the specific heat measurement.

\section{CONCLUSIONS}

NIST Engineering Laboratory is well positioned to make significant contributions to the development of superior room temperature magnetocaloric materials. This report presents a design for a novel test apparatus to directly measure the magnetocaloric effect (MCE), which consists of measuring the internal energy change and the adiabatic temperature change of a magnetocaloric material when exposed to a magnetic field. An apparatus design was presented to measure the MCE of test samples of $5 \mathrm{~g}$ with an estimated uncertainty of $0.6 \%$ and $0.3 \mathrm{~K}$ for the energy change and the temperature change, respectively. The small uncertainties were achieved for the small sample by using the incompressibility of liquid as an amplifier to increase the sensitivity of the energy measurement. The design is expected to enable the evaluation of MC materials as candidates for commercial development while using only a 5 g sample. Drawings, parts list, and required test equipment were specified for the construction of the test apparatus. A calibration technique using a first law approach was outlined.

\section{ACKNOWLEDGEMENTS}

This work was funded by NIST Engineering Laboratory Exploratory Project. Thanks go to Prof. R. Brignoli of The Catholic University of America and to the following NIST personnel for their constructive criticism of the draft manuscript: W. Healy and P. Domanski. 


\section{NOMENCLATURE}

English symbols

A internal surface area of the test chamber $\left(\mathrm{m}^{2}\right)$

$A_{0} \quad$ constant in eq. (C.2) $\left(\mathrm{m}^{3}\right)$

$A_{1} \quad$ constant in eq. (C.2) $\left(\mathrm{m}^{3}\right.$-s)

$A_{2} \quad$ constant in eq. (C.2) (J)

$B \quad$ intensity of the magnetic field (T)

$C_{\mathrm{n}=1 . .3}$ fitting constants for pressure-time $\left(\mathrm{Pa}-\mathrm{m}^{-\mathrm{n}}\right)$

$c_{\mathrm{p}} \quad$ specific heat $\left(\mathrm{kJ}^{-} \mathrm{kg}^{-1}-\mathrm{K}^{-1}\right)$

$D_{\text {w }} \quad$ wire diameter (m)

$E \quad$ internal energy of the fluid (J)

$h \quad$ convection heat transfer coefficient $\left(\mathrm{W}-\mathrm{m}^{-2}-\mathrm{K}^{-1}\right)$

$H_{\mathrm{f}} \quad$ total enthalpy of liquid in control volume (J)

$J \quad$ MCE heating effect defined in eq. (16) (J)

$L_{\mathrm{w}} \quad$ length of Nichrome wire (m)

$M_{\mathrm{m}} \quad$ sample material mass $(\mathrm{kg})$

$P \quad$ pressure $(\mathrm{Pa})$

$p_{\mathrm{e}} \quad$ electrical power (W)

$Q_{b} \quad$ heat transferred to the bath (J)

$q \quad$ heat transfer rate to the fluid (W)

$t$ time (s)

$T \quad$ temperature (K)

$U$ expanded measurement uncertainties

$V_{\mathrm{c}} \quad$ fluid chamber volume $\left(\mathrm{m}^{3}\right)$

$V_{\mathrm{e}} \quad$ supplied voltage (V)

$W \quad$ work done on the fluid (W)

Z work parameter in eq. (10) (W)

Greek symbols

$\triangle P \quad$ pressure change $(\mathrm{kPa})$

$\Delta T_{\mathrm{M}} \quad$ adiabatic temperature change $(\mathrm{K})$

$\lambda_{\mathrm{f}} \quad$ liquid specific enthalpy $\left(\mathrm{kJ}^{\left.-\mathrm{kg}^{-1}\right)}\right.$

$\rho$ f liquid density $\left(\mathrm{kg}^{-3} \mathrm{~m}^{-3}\right)$

$\rho_{\mathrm{e}} \quad$ electrical resistivity $(\Omega-\mathrm{m})$

\section{$\underline{\text { Subscripts }}$}

a ambient

b bath

eq equilibrium

f fluid

m magnetocaloric material, minimum

$\mathrm{M}$ maximum

p pulse, peak

$\underline{\text { Abbreviations }}$

AC alternating current 


$\begin{array}{ll}\text { DC } & \text { direct current } \\ \text { MCE } & \text { magnetocaloric effect } \\ \text { NPT } & \text { National Pipe Thread }\end{array}$




\section{REFERENCES}

Aslani, A., Ghahremani, M., Zhang, M., Bennett, L. H., and Della Torre, E. 2016. Enhanced Magnetic Properties of Ni51Mn33.4In15.6 Heusler Alloy Nanoparticles. Journal of Magnetism and Magnetic Material, 401, 35-42.

Bennet, L., 2015. Private communications.

Brown, J. S. and Domanski, P. A. 2014. Review of alternative cooling technologies. Applied Thermal Engineering. 64, 252-262.

De Oliveira, N. A., and von Ranke, P. J. 2010. Theoretical aspects of the magnetocaloric effect. Physic Reports 489, 89-159.

Gómeza, J. R., Garciab, R. F., Catoiraa, A. D., Gómeza, M. Romero. 2013. Magnetocaloric effect: A review of the thermodynamic cycles in magnetic refrigeration, Renewable and Sustainable Energy Reviews, 17, 74-82.

Langebach, R., Klaus, M., Haberstroh C., and Hesse, U. 2014. Magnetocaloric cooling near room temperature - a status quo with respect to household refrigeration. 15th Int. Refr. \& Air Cond. Conf. at Purdue.

Lee, J. S. 2004. Evaluation of the magnetocaloric effect from magnetization and heat capacity data. Phys. Stat. sol. 240(7) 1765-1768; doi 10.1001/pssb.20004685.

Lee, S. J., Kenkel, J. M., Pecharsky, V. K., and Jiles, D. C. 2002. Permanent magnet array for the magnetic refrigerator. Journal of Applied Physics 91, 8894; doi: 10.1063/1.1451906

McMichael, R. D., Shull, R. D., Swartzendruber, L. J., Bennett, L.H., and Watson, R. E. 1992. Magnetocaloric effect in superparamagnets, Journal of Magnetism and Magnetic Materials, 111, 29-33.

Nara, K. 2005. Study of the Magnetic Field Effect on Commercial Thermistors using a Water Triple Point. Japanese Journal of Applied Physics, 44(3), 1506-1507.

Pecharsky, V. K. and Gschneidner, K. A., Jr. 2001. Some common misconceptions concerning magnetic refrigerant materials, J. Appl. Phys., 90(9), 4614-4622.

Pecharsky, V. K. and Gschneidner, K. A., Jr. 1999. Magnetocaloric effect and magnetic refrigeration, J. Magnetism and Magnetic Materials., 200, 44-56.

Vodyanoy, V. J., and Mnyukh, Y. 2013. The physical nature of "giant” magnetocaloric and electrocaloric effects. American Journal of Materials Science. 3(5): 105-109; doi:10.5923/j.materials.20130305.01

Yu, B., Liu, M., Egolf, P. W., Kitanovski, A. 2010. A review of magnetic refrigerator and heat pump prototypes built before the year 2010. Int. J. Refrig. 33, 1029-1060. 
Table 1: List of Test Apparatus Parts and Equipment

\begin{tabular}{|c|c|c|}
\hline Component & Model Number/Product Description & Website Link \\
\hline $\begin{array}{l}\text { pulse } \\
\text { generator }\end{array}$ & Agilent \# 81104A & $\begin{array}{l}\text { http://www.testequipmentdepot.com/agil } \\
\text { ent/pulsegenerators/81110a.htm }\end{array}$ \\
\hline bar magnet & $\begin{array}{c}\text { B7512 } \\
(75 \text { x } 25 \text { x 12) mm N38 NiCuNi Plated } \\
\text { Block Magnet }\end{array}$ & $\begin{array}{c}\text { http://www.gaussboys.com/store/index.p } \\
\text { hp/magnet-shapes/blocks/b7512.html }\end{array}$ \\
\hline $\begin{array}{l}\text { Linear } \\
\text { positioner }\end{array}$ & $\begin{array}{c}\text { Deltron Slide model 1201-series } 2200 . \\
\text { Custom build with leadscrew and } \\
\text { nonmagnetic materials. Bill Schully knows } \\
\text { the details 800-245-5013 }\end{array}$ & $\begin{array}{l}\text { http://linear- } \\
\text { positioners.com/search/Micrometer_Posi } \\
\text { tioning_Stages_Model.aspx?pkid=2535 }\end{array}$ \\
\hline Gaussmeter & $\begin{array}{c}\text { Model } 460 \text { 3-Channel Gaussmeter by Lake } \\
\text { Shore Cryotronics }\end{array}$ & $\begin{array}{c}\text { http://www.lakeshore.com/products/Gau } \\
\text { ssmeters/Model-460-3-Channel- } \\
\text { Gaussmeter/Pages/Overview.aspx }\end{array}$ \\
\hline Hall sensor & HST-1 & $\frac{\text { http://www.lakeshore.com/products/Hall }}{\text {-Probes/Pages/ProbeGuide.aspx }}$ \\
\hline $\begin{array}{l}\text { pressure } \\
\text { transducer }\end{array}$ & (1/2” male NPT) & $\frac{\text { http://www.astsensors.com/mems- }}{\text { pressure-sensor-technology.php }}$ \\
\hline valve & $\begin{array}{c}\text { Hoke double block \& bleed gauge valve } \\
\text { model-HM8322 }\end{array}$ & $\begin{array}{l}\frac{\text { http://www.hoke.com/Catalogs/Catalog }}{\text { ENG_HOKE_HM_Series_Standard_Val }} \\
\text { ves_10.22.14.pdf }\end{array}$ \\
\hline $\begin{array}{l}\text { temperature } \\
\text { sensor }\end{array}$ & Thermistor T320/E320 Series & $\frac{\text { https://www.thermistor.com/t320e320- }}{\underline{\text { series }}}$ \\
\hline $\begin{array}{l}\text { Data } \\
\text { acquisition }\end{array}$ & Agilent 34970A/34972A & $\begin{array}{l}\frac{\underline{\text { http://www.keysight.com/en/pd- }}}{\frac{1000001313 \% 3 A \text { Aepsg\%3Apro-pn- }}{34970 \mathrm{~A} / \text { data-acquisition-data-logger- }}} \\
\text { switch-unit?cc=US\&lc=eng}\end{array}$ \\
\hline $\begin{array}{l}\text { Nichrome } \\
\text { wire }\end{array}$ & $\begin{array}{c}\text { Omega NI60-040-200 (18 gage }= \\
1.024 \mathrm{~mm})\end{array}$ & http://www.omega.com/pptst/NI60.html \\
\hline $\begin{array}{l}\text { Temperature } \\
\text { bath }\end{array}$ & Fluke Model 7103 & $\begin{array}{l}\text { http://www.tequipment.net/Fluke7103- } \\
\underline{\text { 156.html?v=7540\#tab-specifications }}\end{array}$ \\
\hline Oscilloscope & $\begin{array}{c}\text { Rigol MSO2202A-S Mixed Signal } \\
\text { Oscilloscope } 200 \mathrm{MHz}\end{array}$ & $\begin{array}{c}\underline{\text { http://www.tequipment.net/Rigol/MSO2 }} \\
\underline{\text { 202A-S/Mixed-Signal- }} \\
\text { Oscilloscopes/?v=7233 }\end{array}$ \\
\hline
\end{tabular}


Table 2: Estimated Expanded Uncertainties for Test Apparatus

\begin{tabular}{|c|c|c|c|}
\hline Measurement & Instrument & $U$ & $U(\%)$ \\
\hline $\begin{array}{l}\text { Heat pulse } \\
\text { duration }\end{array}$ & Agilent \# 81104A pulse generator & $U_{\mathrm{tp}}= \pm 1 \mathrm{~ns}$ & $\pm 0.003 \%$ \\
\hline $\begin{array}{l}\text { Heat pulse } \\
\text { duration }\end{array}$ & Oscilloscope & $U_{\mathrm{tp}}= \pm 5 \mathrm{~ns}$ & $\pm 0.015 \%$ \\
\hline Voltage pulse & Agilent \# 81104A pulse generator & $\pm(3 \%+150 \mathrm{mV})$ & $\pm 3 \%$ \\
\hline Heat pulse & Agilent \# 81104A pulse generator & $\pm 3 \%$ & $\pm 3 \%$ \\
\hline $\begin{array}{c}\text { Linear } \\
\text { positioner }\end{array}$ & Deltron Slide model 1201-series 2200. & $\pm 0.02 \mathrm{~mm}$ & $\pm 0.1 \%$ \\
\hline $\begin{array}{l}\text { Magnetic field } \\
\text { intensity }\end{array}$ & $\begin{array}{c}\text { Model } 460 \text { 3-Channel Gaussmeter by } \\
\text { Lake Shore Cryotronics with Hall } \\
\text { Sensor }\end{array}$ & $\pm 0.016 \mathrm{~T}$ & $\pm 1 \%$ \\
\hline Liquid pressure & pressure transducer & $\pm 0.2 \mathrm{kPa}$ & $\pm(0.5-2) \%$ \\
\hline $\begin{array}{l}\text { temperature } \\
\text { sensor }\end{array}$ & Thermistor T320/E320 Series & $\pm 0.1 \mathrm{~K}$ & $\pm 0.03 \%$ \\
\hline DC voltage & Agilent 34970A/34972A & $\pm 0.004 \%$ & $\pm 0.004 \%$ \\
\hline AC voltage & Agilent 34970A/34972A & $\pm 0.06 \%$ & $\pm 0.06 \%$ \\
\hline resistance & Agilent 34970A/34972A & $\pm 0.01 \%$ & $\pm 0.01 \%$ \\
\hline $\begin{array}{c}\text { Bath } \\
\text { temperature }\end{array}$ & Fluke Model 7103 & $\pm 0.25 \mathrm{~K}$ & $\pm 0.07 \%$ \\
\hline$c_{\mathrm{pm}}$ & $\begin{array}{l}\text { DSC in Two Phase Heat Transfer } \\
\text { Laboratory at NIST }\end{array}$ & $\pm 3 \%$ & $\pm 3 \%$ \\
\hline$M_{\mathrm{m}}$ & $\begin{array}{l}\text { Mettler XS1003S in Two Phase Heat } \\
\text { Transfer Laboratory at NIST }\end{array}$ & $\pm 0.002 \mathrm{~g}$ & $\pm 0.04 \%$ \\
\hline$V_{\mathrm{c}}$ & Mettler XS1003S and density of fluid & $\pm 9 \times 10^{-8} \mathrm{~m}^{3}$ & $\pm 1 \%$ \\
\hline
\end{tabular}




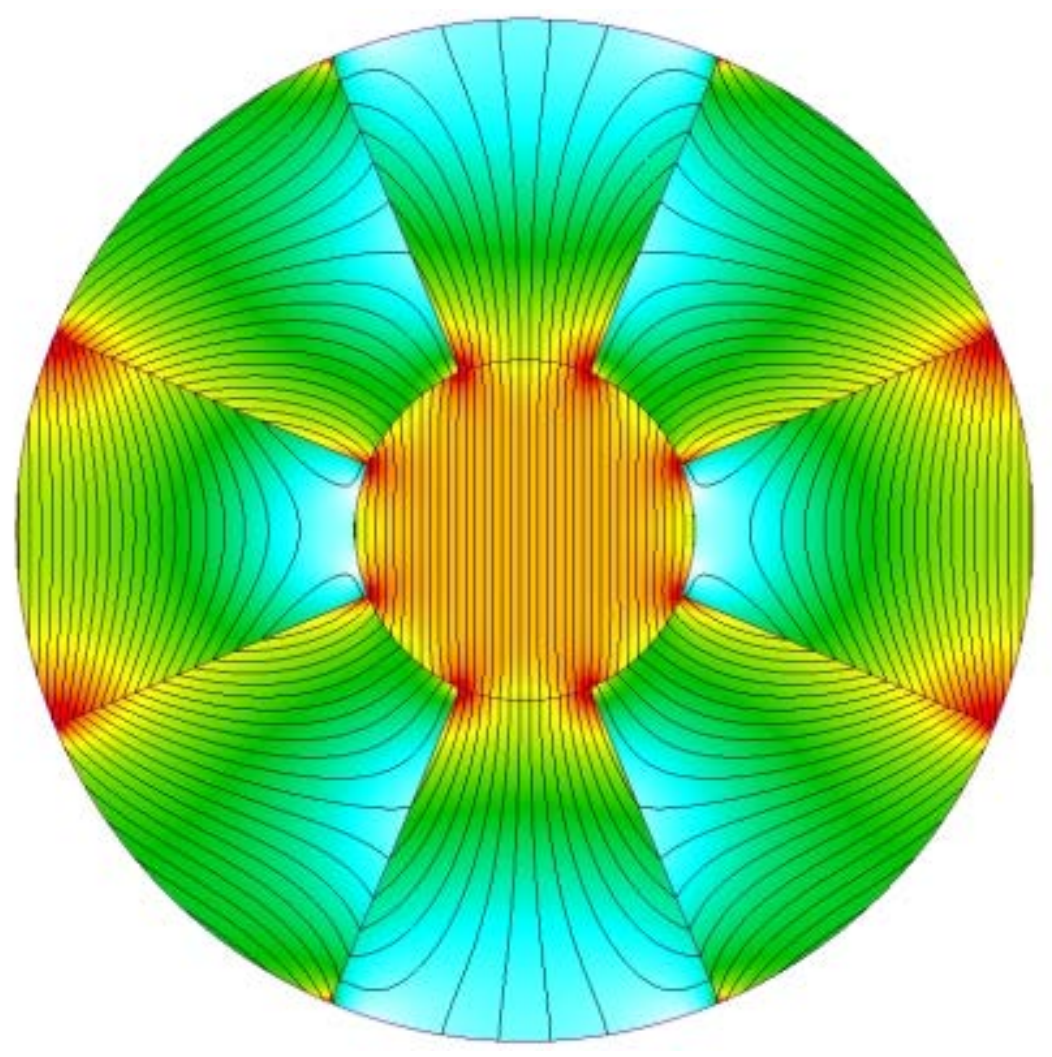

Fig. 1 Halbach magnet with magnetic field lines (Lee, et al., 2002) 


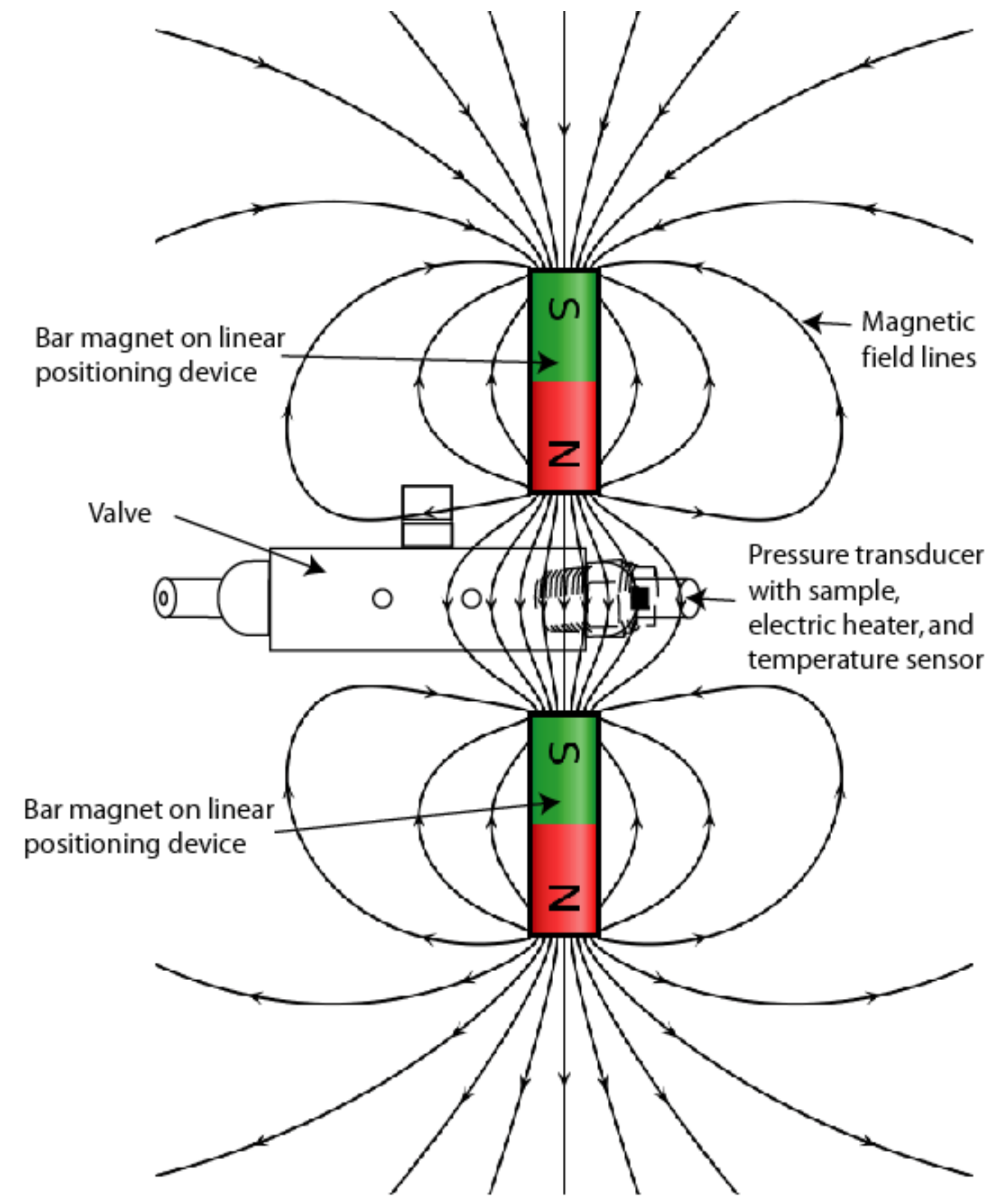

Fig. 2 Simple schematic of test apparatus 


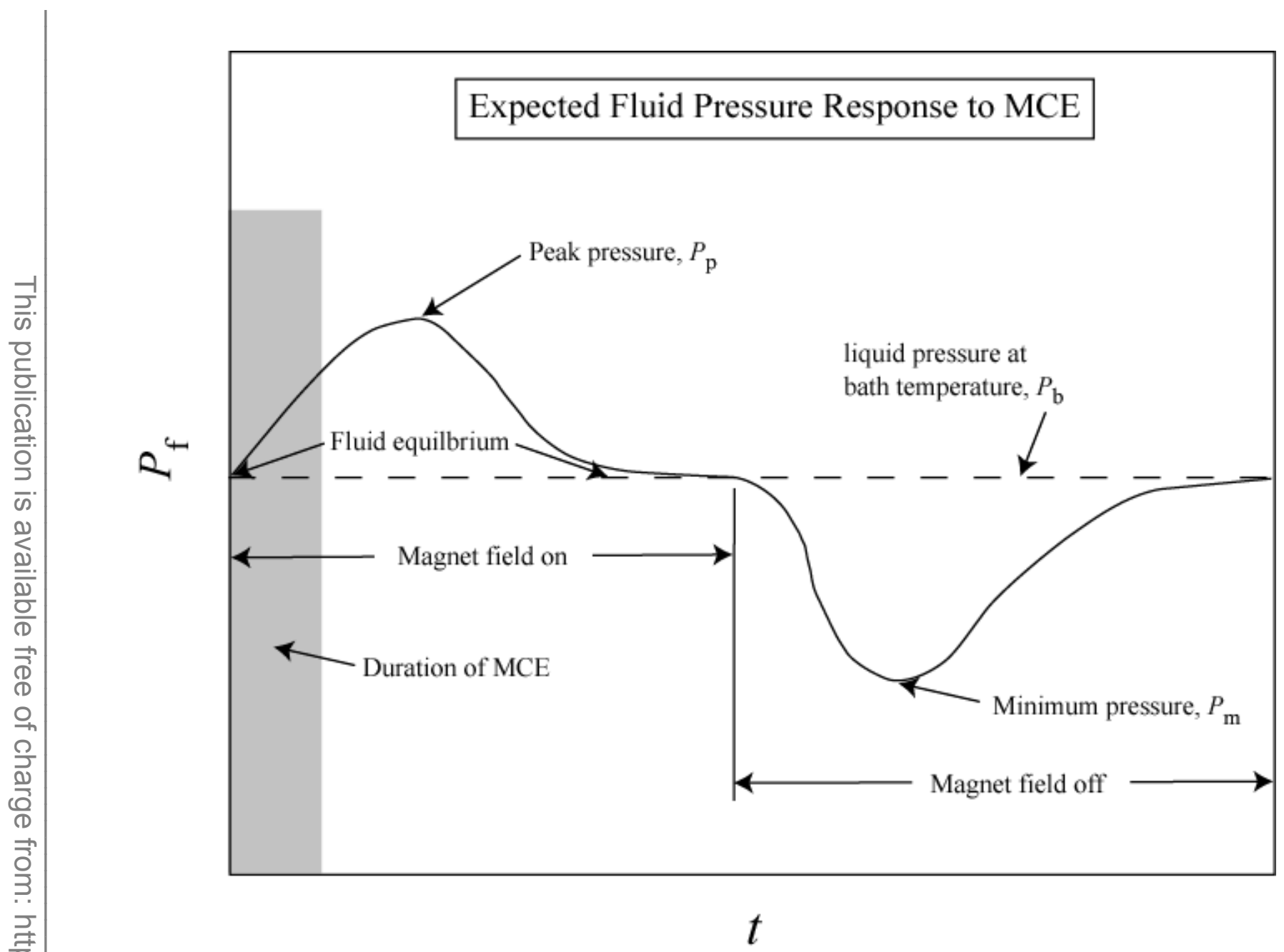

Fig. 3 Transient pressure pulse in test section 


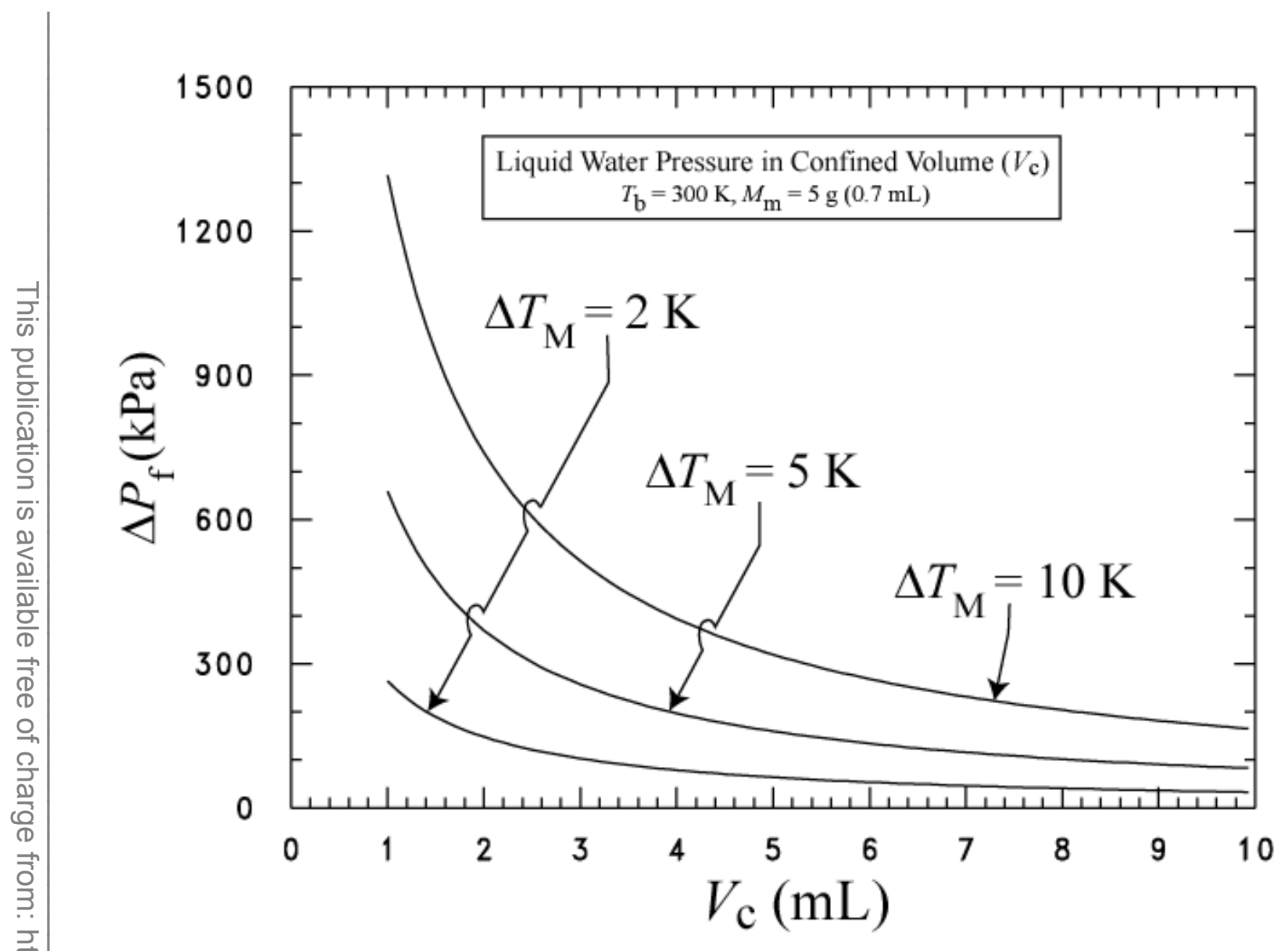

Fig. 4 Change in pressure for various water volumes for a magnetocaloric temperature change of $2 \mathrm{~K}, 5 \mathrm{~K}$, and $10 \mathrm{~K}$ 


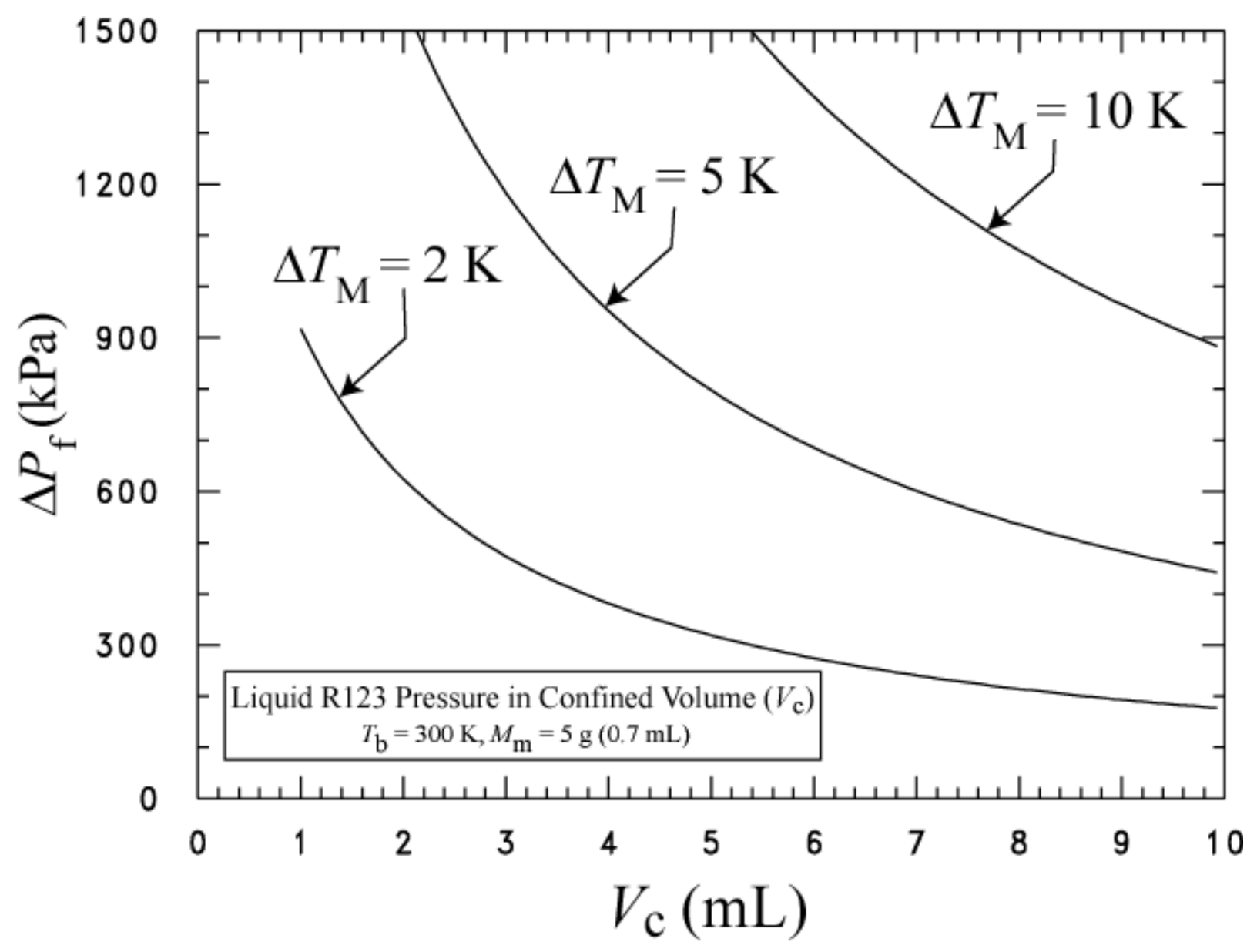

Fig. 5 Change in pressure for various R123 volumes for a magnetocaloric temperature change of $2 \mathrm{~K}, 5 \mathrm{~K}$, and $10 \mathrm{~K}$ 


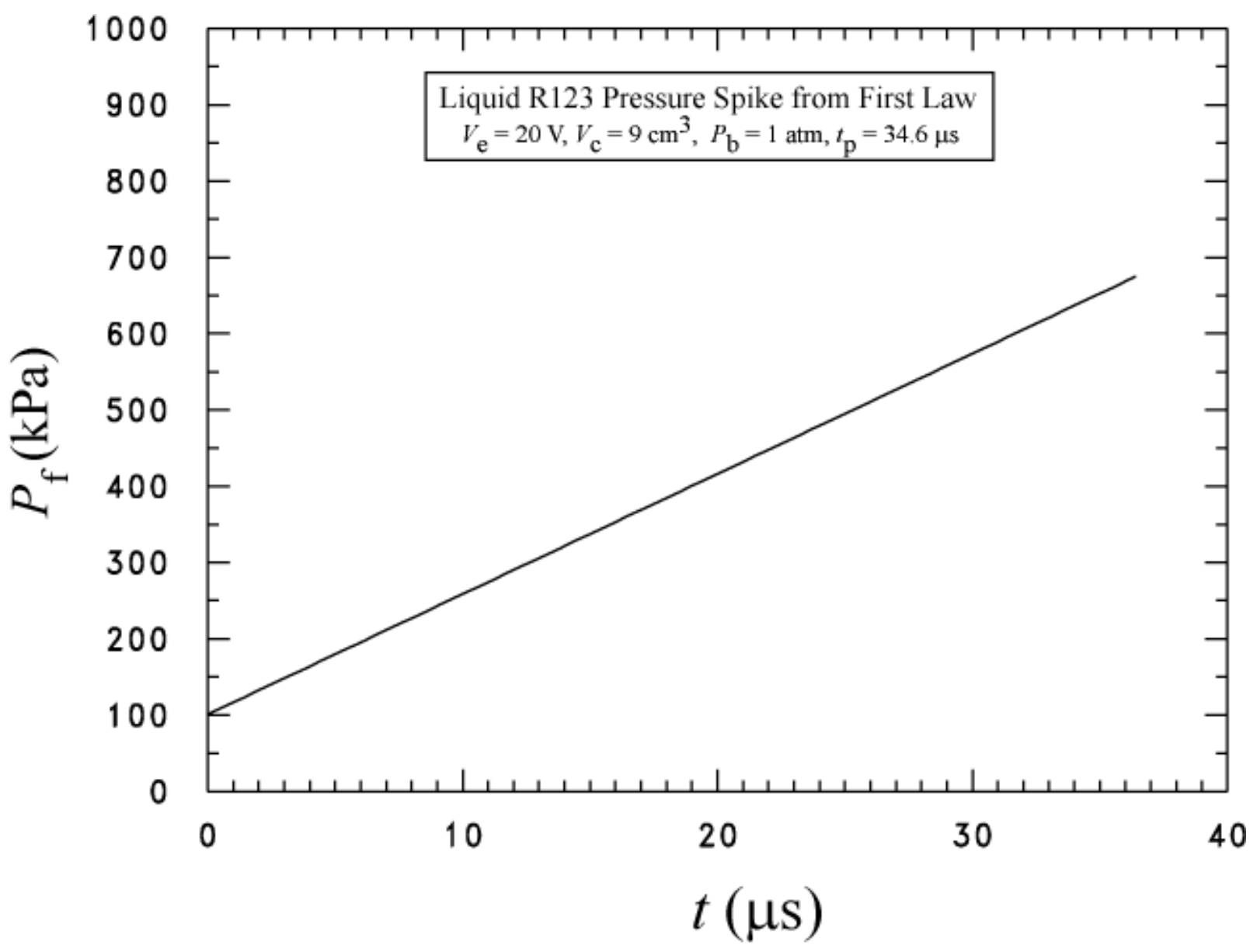

Fig. 6 Example case illustrating the liquid pressure pulse for a volume of $9 \mathrm{~cm}^{3}$ and an applied voltage of $20 \mathrm{~V}$ for $34.6 \mu \mathrm{s}$ 


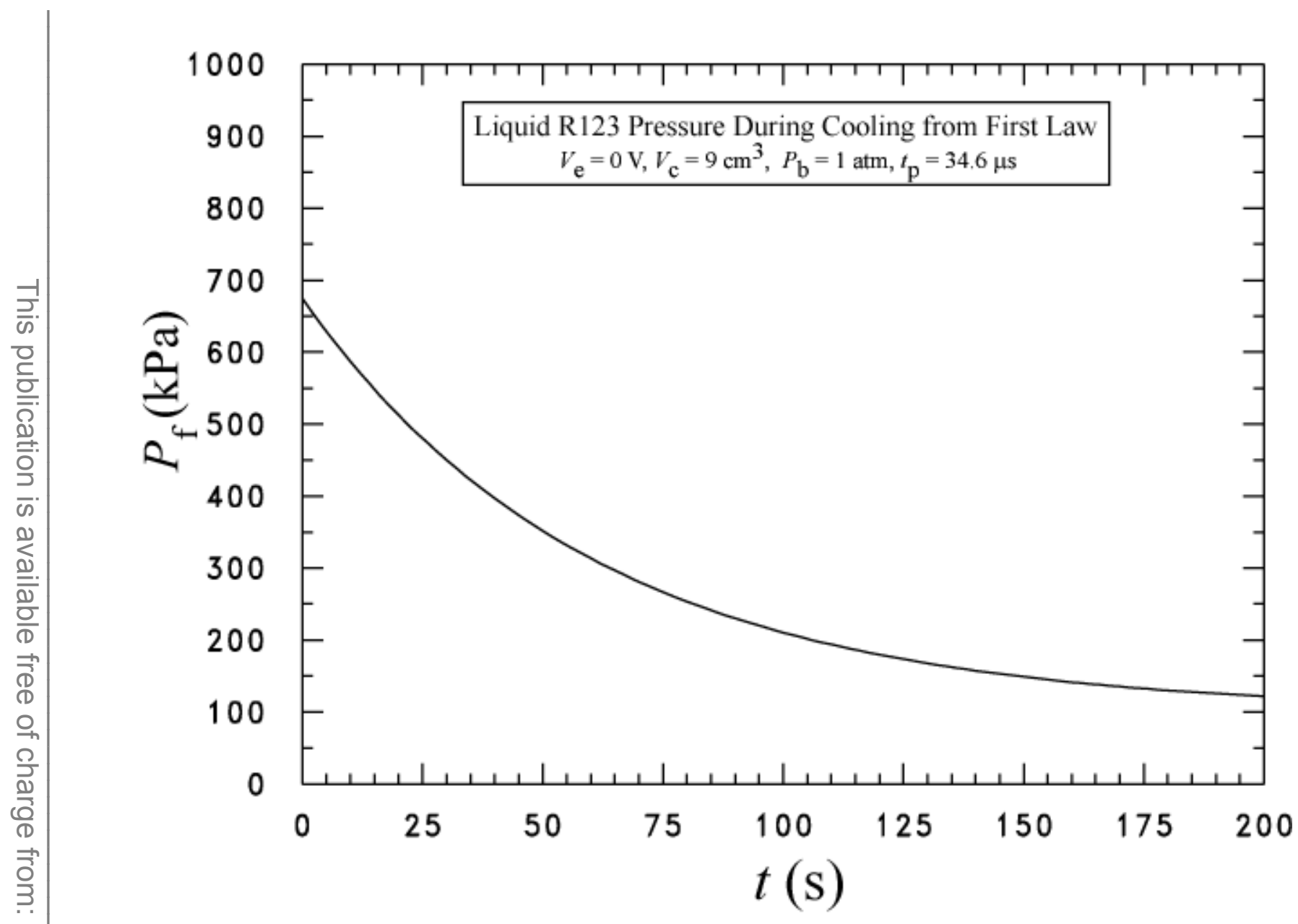

Fig. 7 Example case illustrating the pressure change during cooling after a pulse for a volume of $9 \mathrm{~cm}^{3}$ and an applied voltage of $20 \mathrm{~V}$ for $34.6 \mu \mathrm{s}$ 


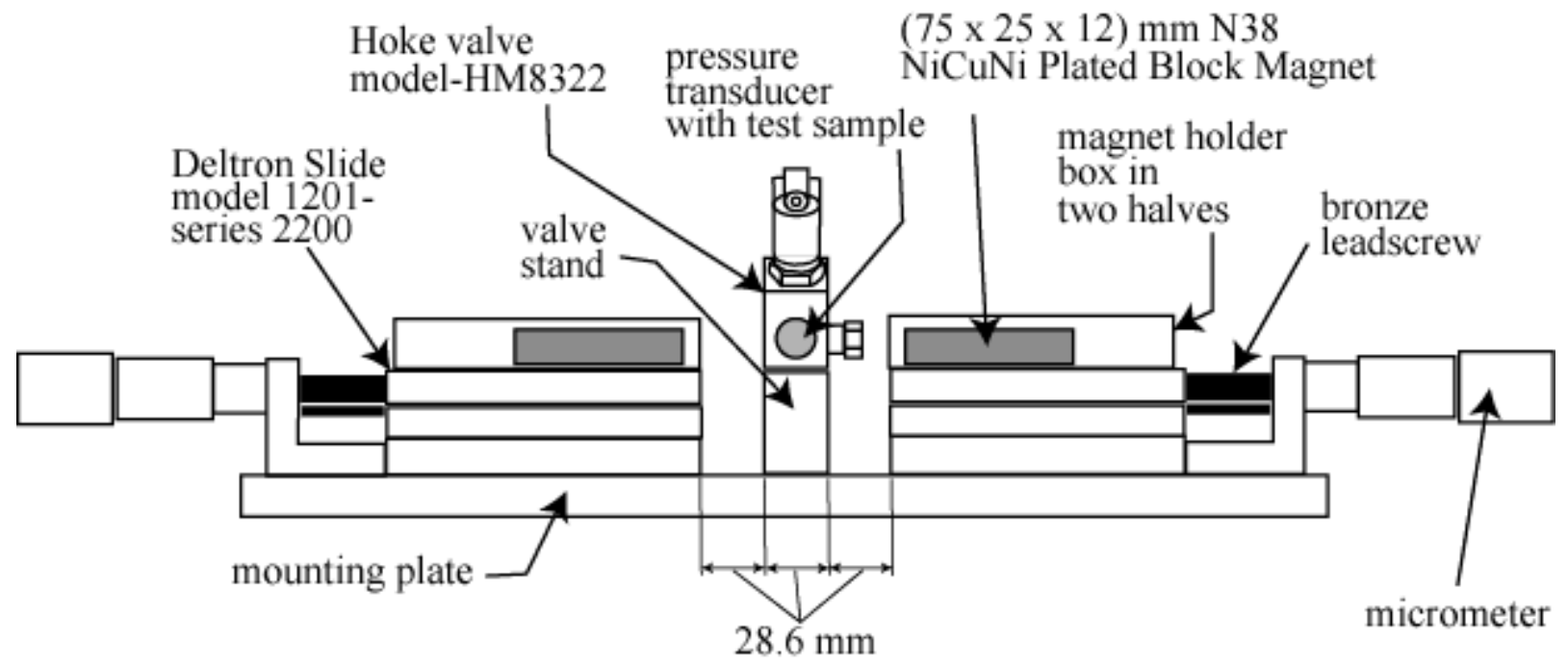

Fig. 8 Side-view schematic of test apparatus 


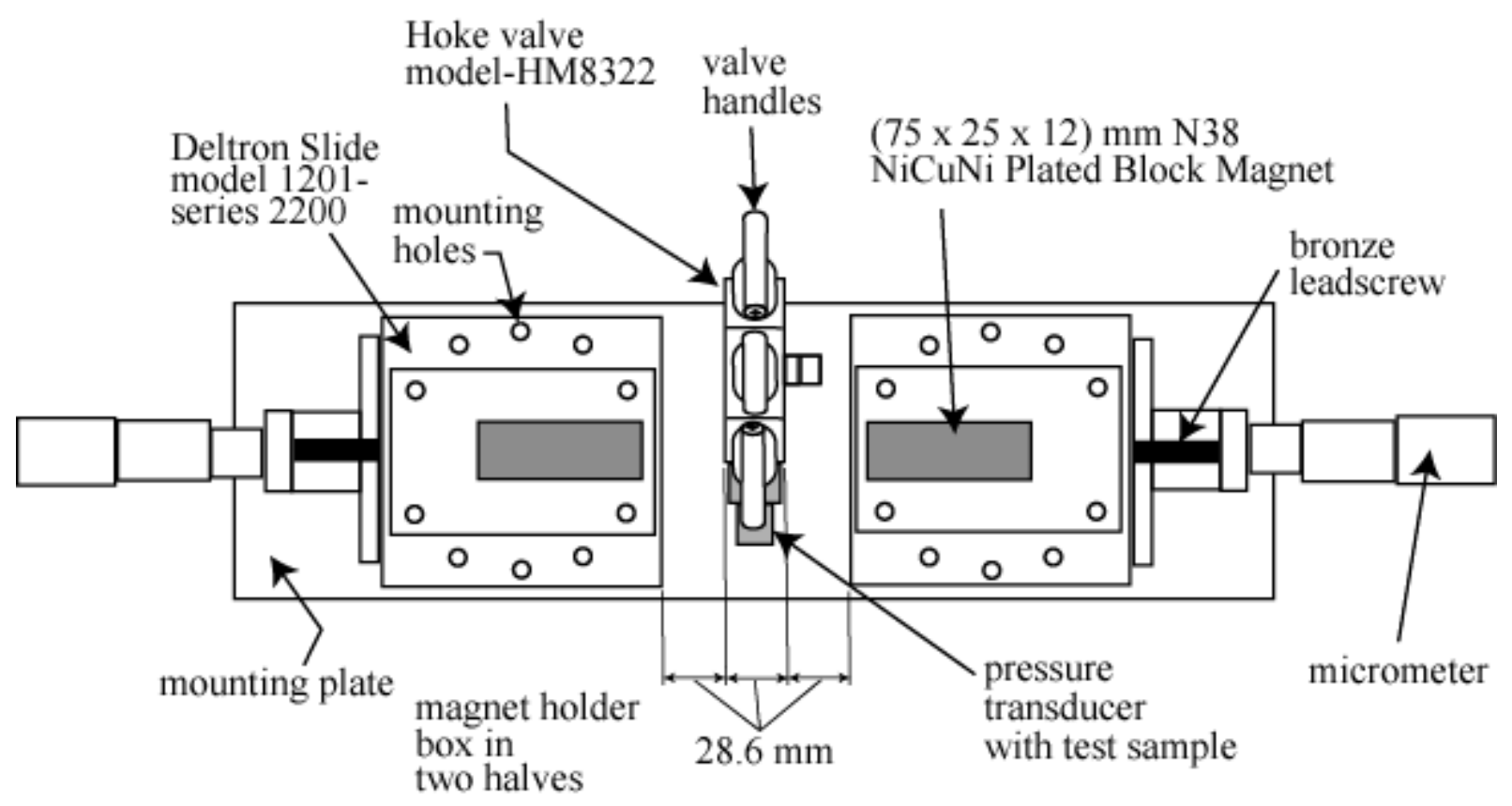

Fig. 9 Top-view schematic of test apparatus 


\section{APPENDIX A: TEST EQUIPMENT}

Commercial test equipment and products are identified here and in Table 1 of this paper in order to specify the test apparatus sufficiently to facilitate its construction. Changes in the availability of test equipment and products may necessitate the re-specification of test equipment and products. In addition, changes in specifications may also arise if we become aware of better equipment or material at the time of test apparatus construction. This appendix is meant to serve as a record from which to begin the building of the test apparatus.

Fig. A.1 Agilent \# 81104A pulse generator

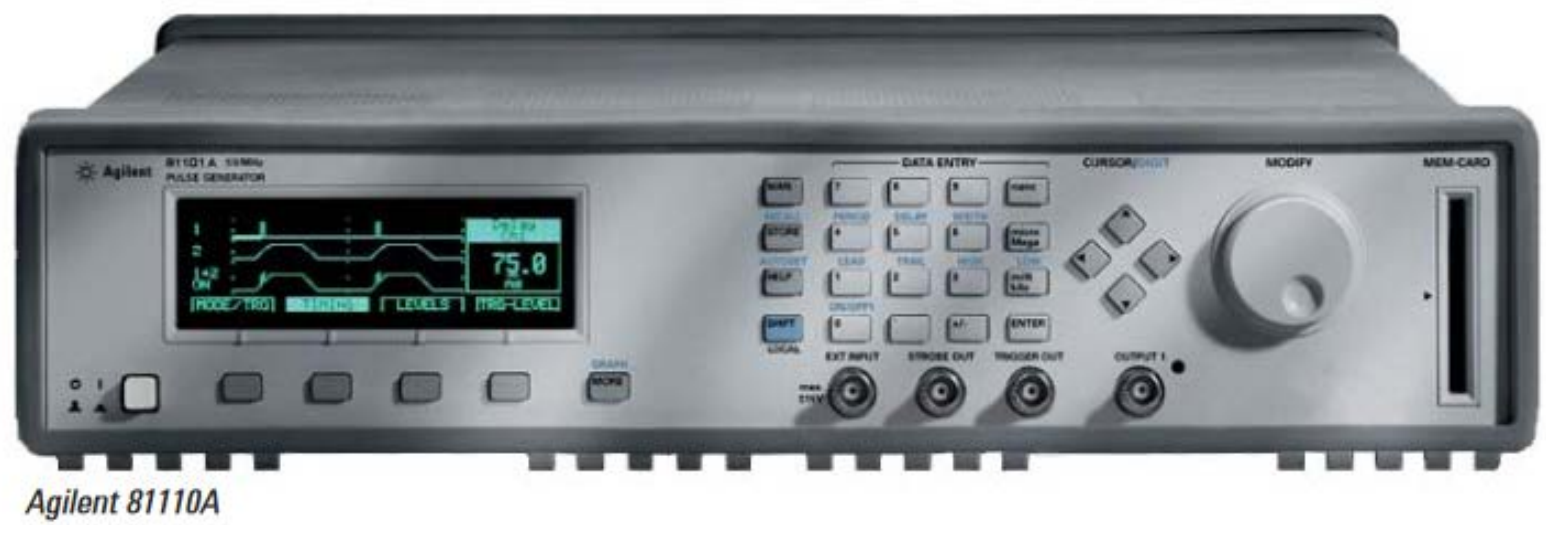

Fig. A.2 Model 460 3-Channel Gaussmeter

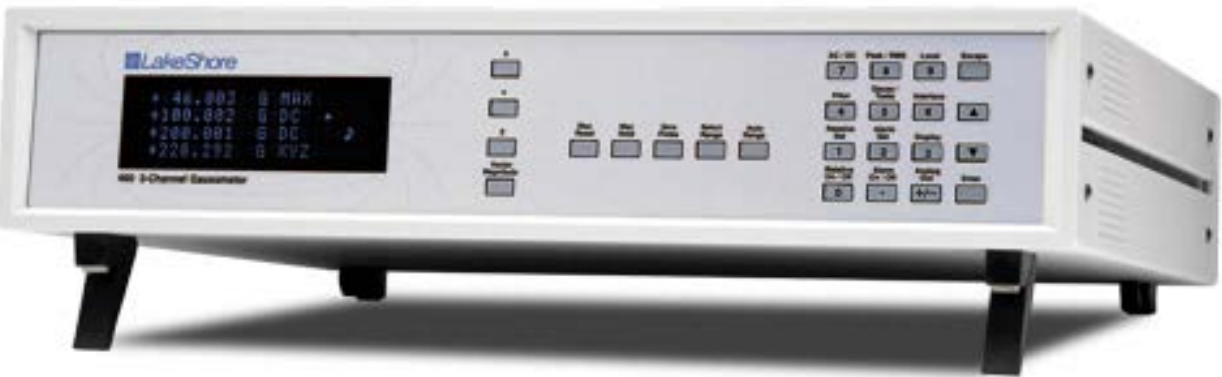




\section{APPENDIX B: PARTS FOR NIST FABRICATION DIVISION}

Magnet Holders: Quantity 2

The bar magnet holder is to be made in two parts. This first, shown below in Fig. B.1, is an aluminum cradle with drill-through holes to match hole positions on the stage of the positioning device. Each dimension of the cavity of the cradle is oversized by approximately $2 \mathrm{~mm}$ as compared to the bar magnet dimensions. The lid, shown in Fig. B.2, is an aluminum plate with drill through holes to match the mounting holes on the cradle. Aluminum wedges will be used to fix the position of the bar magnet within the cavity.

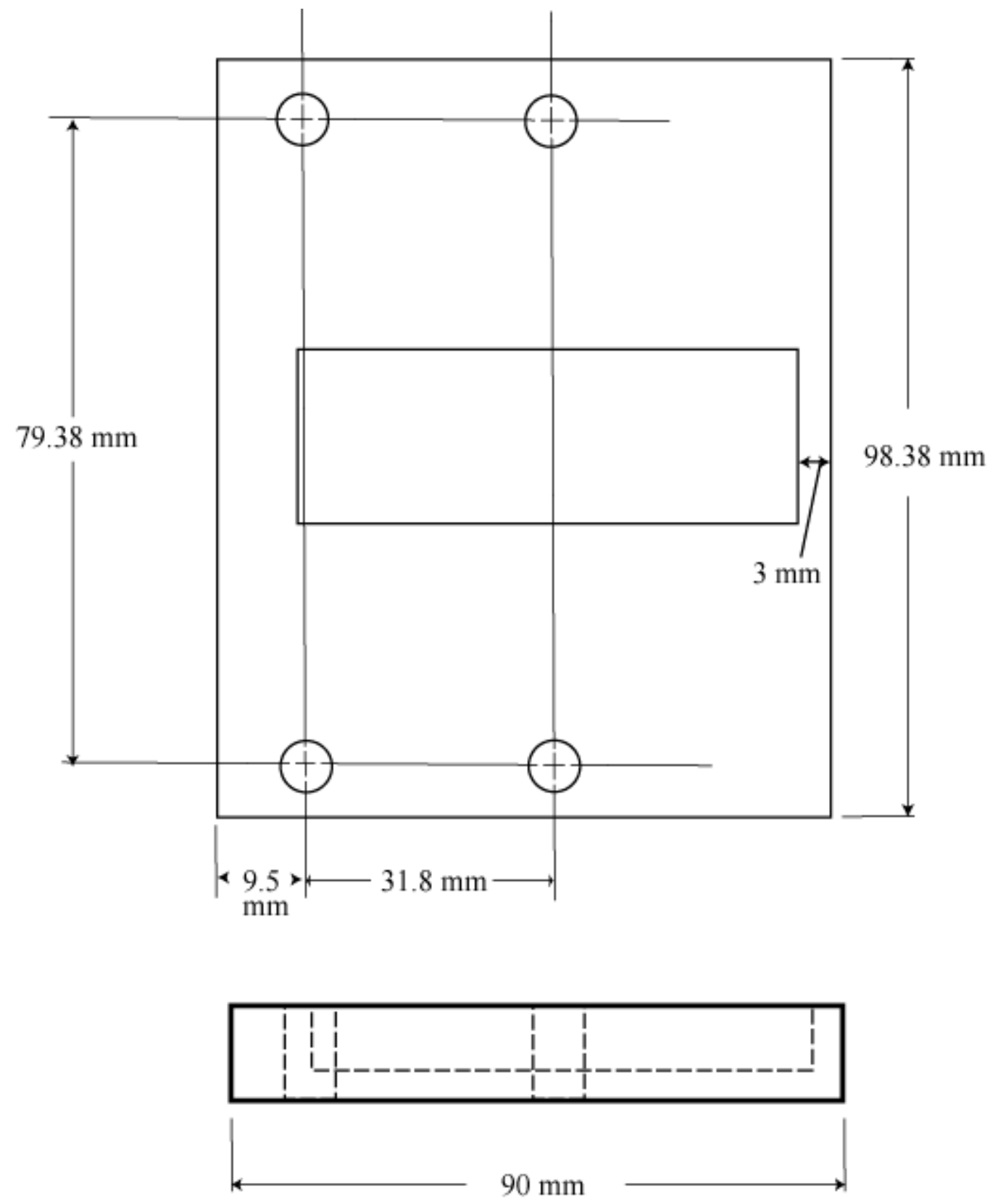

Fig. B.1 Bottom of Bar Magnetic Holder 
The exact positioning of the holes will be determined once the linear positioner has been purchased.

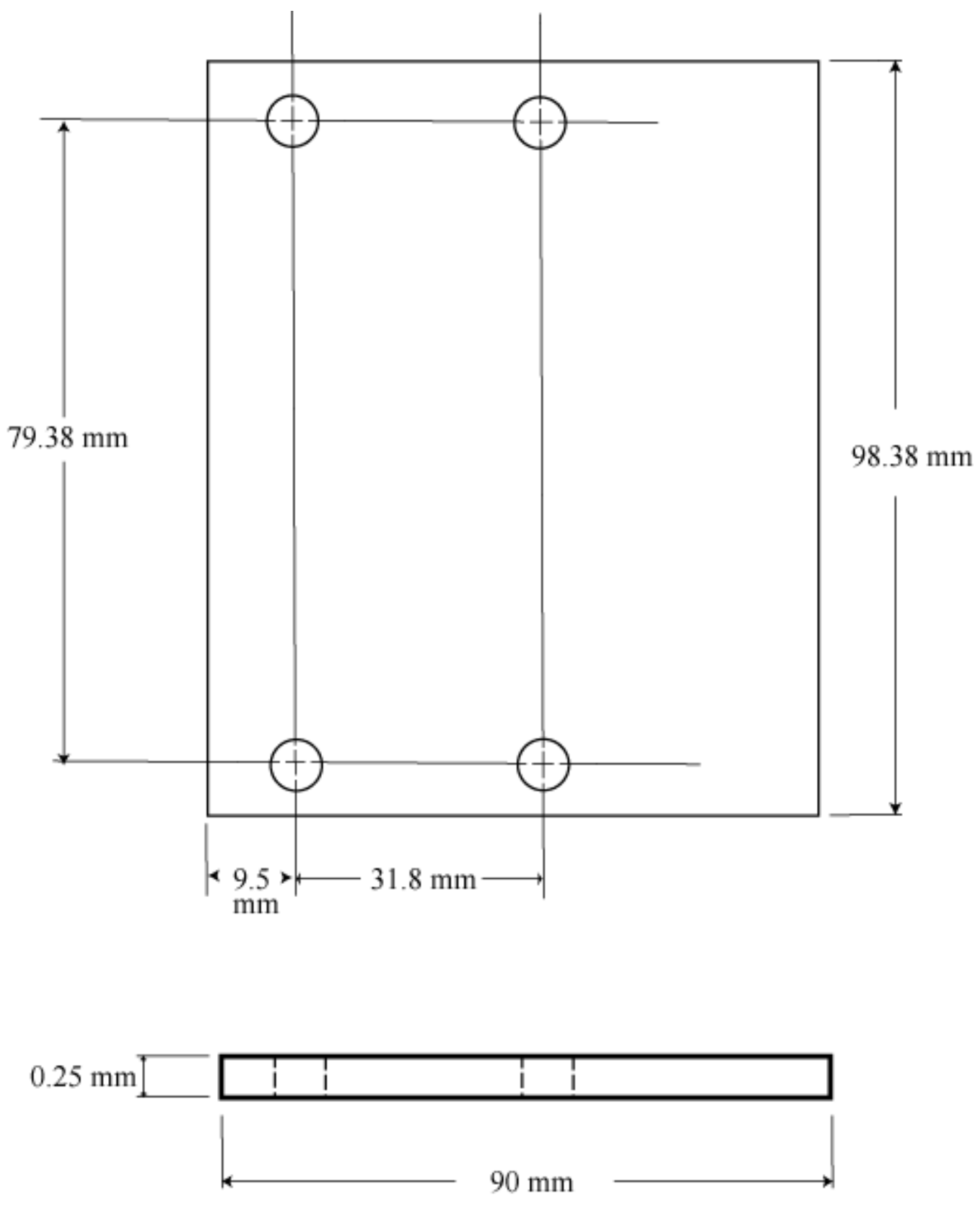

Fig. B.2 Lid for Bar Magnetic Holder 
Mounting Plate

The mounting plate drawing is shown in Fig. A.3. The exact positioning of the holes will be determined once the linear positioner has been purchased. There are eight drill through holes for the two positioners. The center-two holes are drill-through for the valve block.

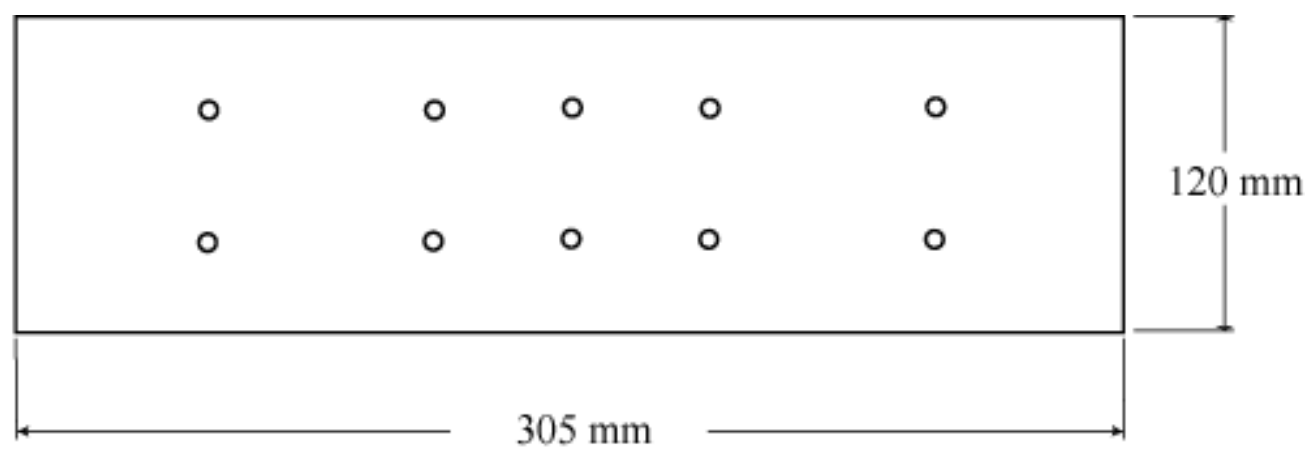
$12.7 \mathrm{~mm}$

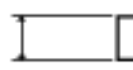
i!
i!
iा
ii
iI

Fig. B.3 Mounting Plate 


\section{APPENDIX C: MCE TEMPERATURE CHANGE FOR POLYNOMIALS}

Because the measured relationship between pressure and time may not be linear as shown in Fig. 6 , expressions are provided for calculating the $\Delta T_{\mathrm{M}}$ for either a quadratic or a cubic fit of pressure with respect to time as appropriate. A cubic relationship between pressure and time is:

$$
P_{\mathrm{f}}=P_{\mathrm{b}}+C_{1} t+C_{2} t^{2}+C_{3} t^{3}
$$

Here the fitting constants are $C_{1}$ through $C_{3}$. The quadratic expression is obtained from eq. (C.1) by setting the constant $C_{3}$ to zero.

The first law of thermodynamics for the test apparatus, eq. (9), can be rewritten in terms of constants:

$$
A_{0}\left(P_{\mathrm{f}}-P_{\mathrm{b}}\right)=\frac{d P_{\mathrm{f}}}{d t} A_{1}+A_{2}
$$

Table C.1 provides the expressions for the $A_{0}$ through $A_{2}$ constants for the four different heat transfer cases that will be measured with the test apparatus.

Substitution of eq. (C.1) and the derivative of eq. (C.1) with respect to time into eq. (C.2) and rearranging to solve for $A_{2}$ yields:

$$
A_{2}=-A_{1} C_{1}+t\left(A_{0} C_{1}-2 A_{1} C_{2}\right)+t^{2}\left(A_{0} C_{2}-3 A_{1} C_{3}\right)+A_{0} C_{3} t^{3}
$$

By substituting $A_{2}$ for $W$ into eq. (14), the $\Delta T_{\mathrm{M}}$ of the magnetocaloric test sample for a cubic $d P_{\mathrm{f}} / d t$ fit is calculated as:

$$
\Delta T_{\mathrm{M}}=\frac{-1}{M_{\mathrm{m}} C_{\mathrm{pm}}} \int_{0}^{t_{\mathrm{p}}} W \mathrm{~d} t=\frac{t_{\mathrm{p}}}{M_{\mathrm{m}} C_{\mathrm{pm}}}\left[A_{1} C_{1}+t_{\mathrm{p}}\left(A_{1} C_{2}-\frac{A_{0} C_{1}}{2}\right)+t_{\mathrm{p}}^{2}\left(A_{1} C_{3}-\frac{A_{0} C_{2}}{3}\right)-\frac{A_{0} C_{3}}{4} t_{\mathrm{p}}^{3}\right]
$$

Here, $t_{\mathrm{p}}$ is the time for the pressure to rise or fall from $P_{\mathrm{b}}$ to either the maximum or the minimum pressure, respectively. Equation (C.4) reduces to the expression for the quadratic pressure fit by setting $C_{3}$ equal to zero. 
Table C.1: Equation (C.2) Constants for MCE Cases

\begin{tabular}{|c|c|c|c|}
\hline \multicolumn{4}{|c|}{ Table C.1: Equation (C.2) Constants for MCE Cases } \\
\hline MCE Case & $A_{0}$ & $A_{1}$ & $A_{2}$ \\
\hline MCE heating & $-\left.h A \frac{d T}{d P}\right|_{\rho}$ & $V_{\mathrm{c}}\left(\rho_{\mathrm{f}} \frac{d \lambda_{\mathrm{f}}}{d P_{\mathrm{f}}}-1\right)$ & $-W$ \\
\hline $\begin{array}{l}\text { Cooling after MCE } \\
\text { heating }\end{array}$ & $-\left.h A \frac{d T}{d P}\right|_{\rho}$ & $V_{\mathrm{c}}\left(\rho_{\mathrm{f}} \frac{d \lambda_{\mathrm{f}}}{d P_{\mathrm{f}}}-1\right)$ & 0 \\
\hline MCE cooling & $-\left.h A \frac{d T}{d P}\right|_{\rho}$ & $V_{\mathrm{c}}\left(\rho_{\mathrm{f}} \frac{d \lambda_{\mathrm{f}}}{d P_{\mathrm{f}}}-1\right)$ & $+W$ \\
\hline $\begin{array}{l}\text { Heating after MCE } \\
\text { cooling }\end{array}$ & $-\left.h A \frac{d T}{d P}\right|_{\rho}$ & $V_{\mathrm{c}}\left(\rho_{\mathrm{f}} \frac{d \lambda_{\mathrm{f}}}{d P_{\mathrm{f}}}-1\right)$ & 0 \\
\hline
\end{tabular}

